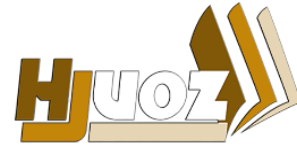

hjuoz.uoz.edu.krd p-ISSN: 2410-7557 e-ISSN: 25185128
كَّوارا زانستيّن مروّقايهتى يا زانكوّيا زاخوّ

مجلة العلوم الانسانية لجامعة زاخو

Humanities Journal of University of Zakho (HJUOZ)

Vol. 5, No. 4, pp. 1154-1168, December-2017

\title{
مسارات البطالة ومحدداته في المملكة الأردنية الهاشمية خلال المدة (1991 - 2013)
}

\author{
ابراهيم محمد حسين
}

قسم العلوم المالية والمصرفية، كلية الادارة والاقتصاد، جامعة دهوك، أقليم كردستان - العراق •

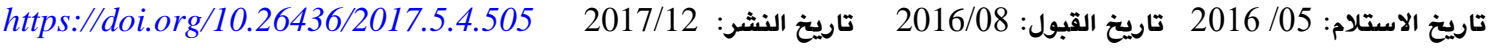

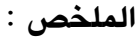

تهدف هذه الدراسة إلى تحليل اتجاهات ومحددات البطالة في المملكة الأردنية الهاشمية بالاعتماد على البيانات السنوية لمعدل البطالة كمتغير معتمد وعدد من المتغيرات المستقلة المتمثلة بـ (عرض النقد، المساعدات الخارجية، النفقات الاستثمارية الحكومية، عدد السكان، معدل التضخم، سعر الفائدة الحقيقي، إجمالي التكوين الرأسمالي الثابت، الناتج المحلي الإجمالي) ولسلسلة زمنية تمتد من سنة 1991 ولغاية 2013، وتبين من خلال الدراسة بأن معدلات البطالة كانت مرتفعة لدى الإناث مقارنة مع الذكور حيث بلغ المتوسط الإسط الحسابي لمعدل البطالة لدى الإناث (25.10\%) في حين بلغ المتوسط لدى الذكور (12.47\%) خلال مدة الدراسة “ بالإضافة إلى ذلك فان معدل البطالة كان شديد الحساسية للتغيرات الحاصلة في النفقات الاستثمارية الحكومية وسعر الفائدة الحقيقي في حين كان أقل حساسية للتغيرات الحاصلة في عرض النقد، المساعدات الخارجية، معدل نمو السكان، معدل التضخم، إجمالي التكوين الرأسمالي

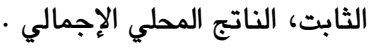

الكلمات الدالة: مفهوم البطالة، قياس معدل البطالة، مسارات البطالة، محددات البطالة، الأردن.

سلبية على النسيج الاجتماعي للمجتمعات وعلى كافة مجالات الاقتصاد القومي. وتعد البطالة أحد المؤثرات الرئيسة التي تعكس حالة اختلال التوانن العام في الاقتصاد القومي، ويالتالي فهي تعد مشكلة معقدة ومتعددة الجوانب، فليس معنى البطالة تعطل نسبة ملموسة من الأفراد عن العمل، لكنها في حقيقة الأمر مشكلة مركبة، نظرا لما تحدثه من آثار سلبية مباشرة على النشاط الاقتصادي، لذلك تسعى كافة الدول قدر الإمكان للتخلص من هذه المشكلة عن طريق استيعاب الطاقات المعطلة الموجودة لديها سواء كانت بشرية أم مادية (أي عنصر من عناصر (الإنتاج) ويعاني الأردن حاله حال بقية الدول من مشكلة البطالة، وهناك العديد من المتغيرات الاقتصادية والاجتماعية والمالية والنقدية التي تؤثر على مي مئى معدل البطالة مثل (عرض النقد، المساعدات الخارجية، النفقات الاستثمارية، معدل نمو السكان، معدل التضخم، سعر الفائدة الحقيقي، إجمالي التكوين الرأسمالي الثابت، الناتج المحلي الإجمالي وغيرها) لذا تحاول هذه الدراسة الإحاطة بتلك العوامل وتحليلها لمعرفة مدى تأثيرها

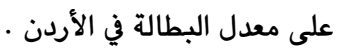

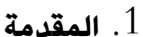

تعتبر البطالة من المواضيع التي استحوذت على جزء كبير من الدراسة والاهتمام من قبل الاقتصاديين والباحثين، حيث تعمقت الأبحاث وتعددت النظريات الاقتصادية التي حاولت تفسير هذه الظاهرة سعيا من خلال تلك الأبحاث والدراسات إلى زيادة حجم العمالة وتخفيض معدلات البطالة ويالذي يعد من أهم الأهداف الاقتصادية والاجتماعية والسياسية للمخططين وواضعي السياسات الاقتصادية. تمثل مشكلة البطالة إحدى أهم المشكلات التي تواجه دول العالم باختلاف مستويات تقدمها وأنظمتها الاقتصادية والاجتماعية والسياسية، فلم تعد البطالة مشكلة تعاني منها الدول النامية فحسب، بل أصبحت واحدة من أخطر مشاكل الدول المتقدمة، ولعل وأبرز سمات الأزمة الاقتصادية العالمية التي تواجهها جميع الدول على حد سواء تتمثل في تفاقم مشكلة البطالة، إذ أن مناك نسبة كبيرة من العاطلين عن العمل موزعين على مختلف أنحاء العالم. ويمكن القول أن البطالة ظاهرة ذات أبعاد اقتصادية يتبين من ظهورها وجود خلل في النشاط الاقتصادي، كما تعتبر في الوقت نفسه ظاهرة اجتماعية لما لها من آثار اجتماعية سلبية على تركيبة المجتمع، وهي من أخطر الأزمات التي يواجهها العالم في الوقت الحاضر، ذلك أنها بلغت مستويات حرجة إلى درجة يمكن أن ينتج عنها كثيرا من الاضطرابات السياسية والاقتصادية والاجتماعية، وكذلك تأثيرات 
1 . إعطاء إطار نظري عن البطالة من حيث المفهوم وكيفية القياس.

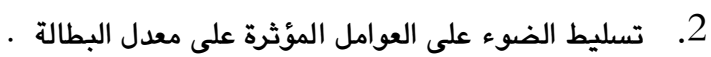

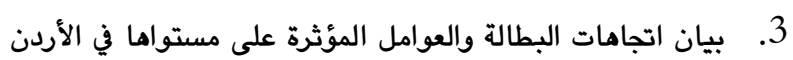
خلال المدة موضوع الدراسة .

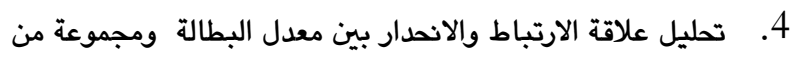
العوامل المؤثرة على مستواها في الأردن خلال المدة موضوع الدراسة. 5.2. متغيرات البحث والمدة الزمنية تم تحليل بيانات سلسلة زمنية سنوية لمدة 23 سنة، وللفترة (1991 - 2013) في الأردن، واعتمد معدل البطالة كمتغير معتمد كنسبة مئوية لكل سنة، أما المتغيرات المستقلة فتمثل بعرض النقد لكل سنة معبرا عنه بمليارات الدنانير، والمساعدات الخارجية لكل سنة معبرا عنها بمليارات الدنانير، والنفقات الاستثمارية لكل سنة معبرا عنها بمليارات الدنانير، ومعدلات النمو السكاني لكل سنة كنسبة مئوية، ومعدل التضخم لكل سنة كنسبة مئوية، وسعر الفائدة الحقيقي لكل سنة كنسبة مئوية، وإجمالي التكوين الرأسمالي الثابت لكل سنة معبرا عنه بمليارات الدنانير، والناتج المحلي الإجمالي لكل سنة معبرا عنه بمليارات الدنانير.

\section{3. الإطار النظري للبطالة ومحدداته}

1.3. تعريف البطالة

برزت ظامرة البطالة في أغلب المجتمعات البشرية منذ أمد بعيد، ولا يكاد مجتمع من المجتمعات البشرية يخلو من هذه الظاهرة بشكل أو بأخر · إلا أن هذه المشكلة أثارت الاهتمام بشكل واضح خلال

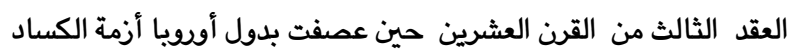

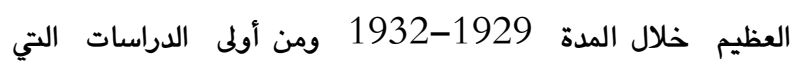
وصفت البطالة كمشكلة اجتماعية واقتصادية خاضعة للمنهج العلمي في الدراسة و التحليل بهدف إدراك حجمها وتحديد مسبباتها و أثارها في المجتمع تلك التي نشرت في عام 1933 من قبل الباحث والتي عمدت إلى وصف الآثار المدمرة لمشكلة (Jahoda et al ) البطالة في إحدى المدن النمساوية، ومنذ تلك المدة الزمنية أضحت إلى البطالة مشكلة أكثر وضوحاً تعاني منها المجتمعات البشرية

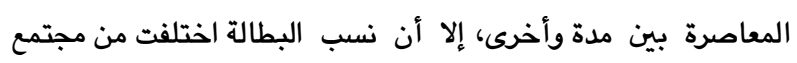
إلى أخر، كما أن كيفية التعامل معها أخذت أساليب مختلفة من التجاهل التام إلى الدعم الكلي أو الجزئي. إن البطالة في أوسع معانيها تعني عدم إنهات

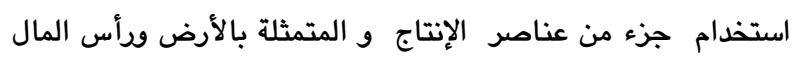

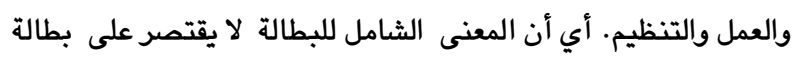
عنصر العمل بل تشمل بطالة أي عنصر من عناصر الإنتاج و لكن جرى في العرف الاقتصادي استخدام مصطلح البطالة للتعبير عن عدم استخدام كل عناصر العمل · (كرمافى، 2013 : 18)

\section{2. منهجية البحث}

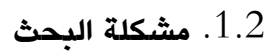

ان تفشي ظاهرة البطالة بين أفراد المجتمع مشكلة بحد ذاتها نظرا لآثارما السلبية على المجتمع، ولارتباطها الوثيق بالعديد من النواحي

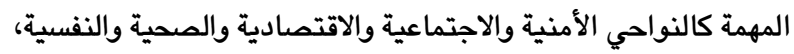
لذا ينبغي على الحكومات تخفيض نسب ومعدلات البطالة قدر الإمكان

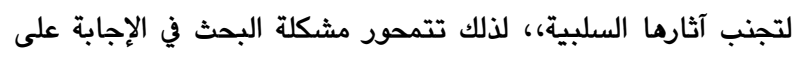

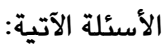
1. ماهي اتجاهات معدلات البطالة في المملكة الاردنية الهاشمية . 2. ماهي العوامل المؤثرة على معدلات البطالة في المملكة الاردنية الهاشمية .

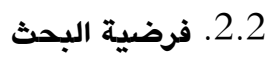
يستند البحث على الفرضيات الآتية :

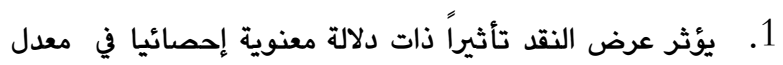
البطالة ويتوقع أن تكون العلاقة بينهما عكسية .

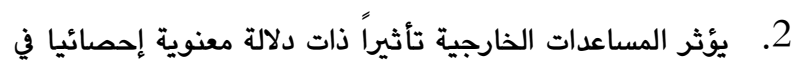
معدل البطالة ويتوقع أن تكون العلاقة بينهما عكسية .

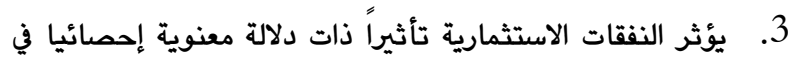
معدل البطالة ويتوقع أن تكون العلاقة بينهما عكسية .

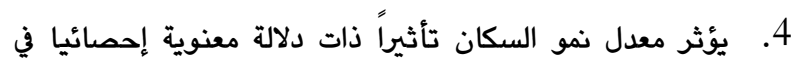
معدل البطالة ويتوقع أن تكون العلاقة بينهما طردية .

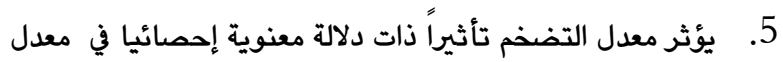
البطالة ويتوقع أن تكون العلاقة بينهما عكسية .

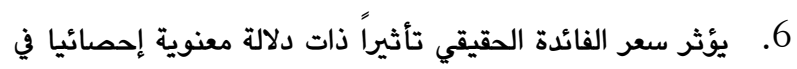
معدل البطالة ويتوقع أن تكون العلاقة بينهما طردية .

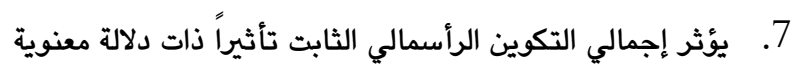
إحصائيا في معدل البطالة ويتوقع أن تكون العلاقة بينهما عكسية .

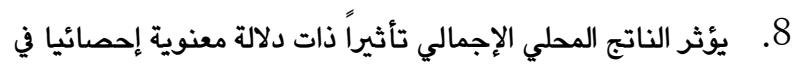
معدل البطالة ويتوقع أن تكون العلاقة بينهما عكسية .

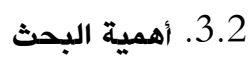
يعد توفير فرص العمل المناسبة لأفراد المجتمع مطلبا وتحديا لأغلب الحكومات التي تحاول التغلب على هذه المشكلة من أجل تحجيم عدد العاطلين عن العمل ويالتالي تعزيز روابط الانتماء والالتزام الاجتماعي بين الفرد والمجتمع من جهة والحكومة من جهة أخرى، لذا فان أهمية البحث تتمثل في مدى سعي الحكومة الأردنية بتبني الإجراءات والسياسات لحل مشكلة البطالة وتوفير فرص العمل لأفراد المجتمع عن طريق التحكم بالعوامل والمتغيرات الواجب التأثير عليها للحد من هذه المشكلة وتخفيف آثارما إلى أدنى حد ممكن . 4.2. هدف البحث يسعى البحث إلى تحقيق الأهداف الآتية : 
3. أن يكون راغباً في العمل، ومستمراً في البحث عنه.

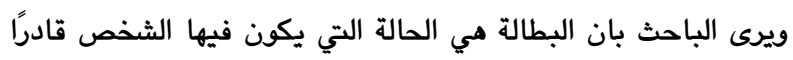
على العمل وراغبًا فيه، ولكن لا يجد العمل والأجر المناسبين. 2.3 - 2.3 قياس معدل البطالة يعتبر مؤشر البطالة مؤشرا اقتصاديا ذو دلالة وأهمية خاصة لأنه يعتبر

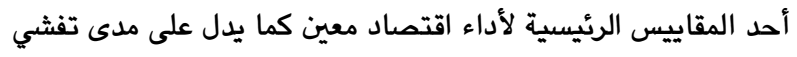

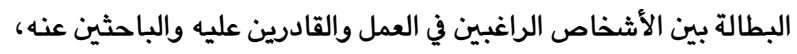
ويتم قياس البطالة بمعدل البطالة وهي نسبة غير المشتغلين

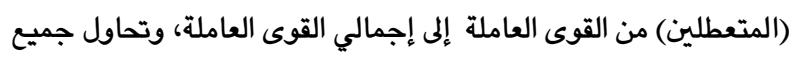
الدول على إبقاء هذا المعدل منذفضا قدر الإمكان للتخفيف من آثاره السلبية البية ويتم التعبير عن معدل البطالة بالصيغة الآتية :

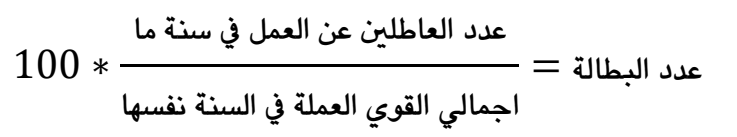

$$
\begin{aligned}
& \text { إجمالي القوى العاملة في السنة نفسها }
\end{aligned}
$$

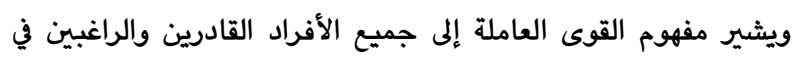

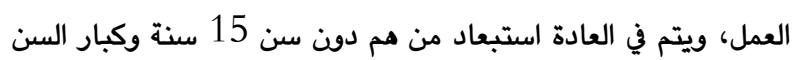

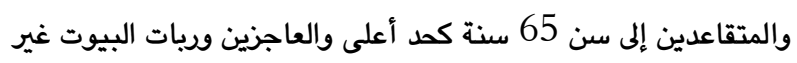
الراغبات في العمل والطلاب بأنواعهم · (الوزني والرفاعي، 2006 :

\section{3. - العوامل المؤثرة في البطالة:}

هناك العديد من العوامل المؤثرة على مستوى البطالة ومن أهمها :

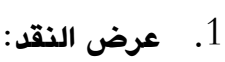

تخضع كمية النقود المعروضة لسيطرة البنك المركزي المسؤول عن

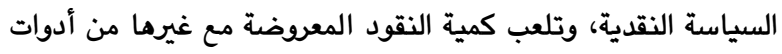

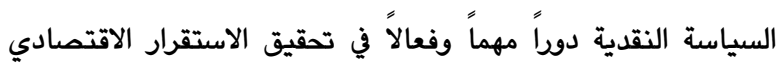

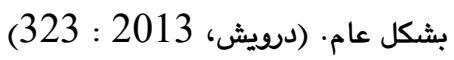
فعند قيام البنك المركزي بأتباع سياسة نقدية توسعية من خلال قيامه بشراء السندات الحكومية فان ذلك يؤدي إلى ارتفاع أسعار الأوراق

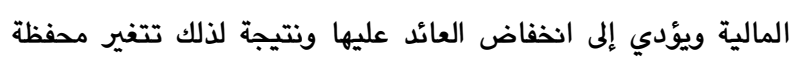

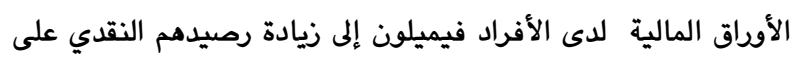

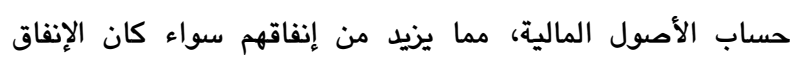

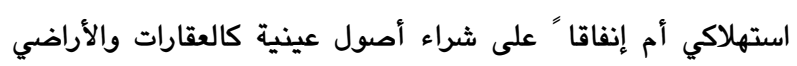
ويترتب على هذه الزيادات في الإنفاق زيادة في المستوى العام للأسعار، أنساء

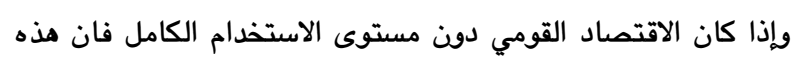

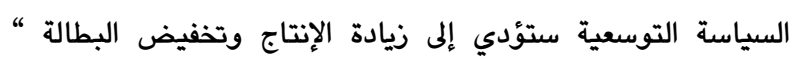

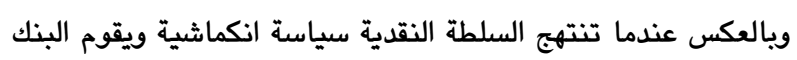

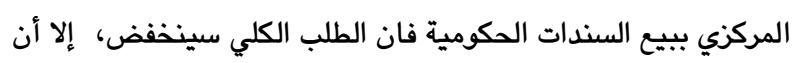

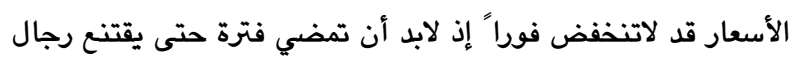

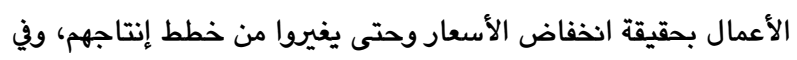

و فيما يخص التعريف الذي طرحته دائرة المعارف الأمريكية من

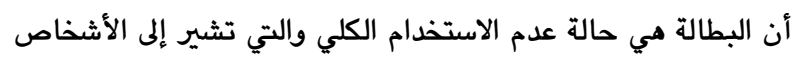

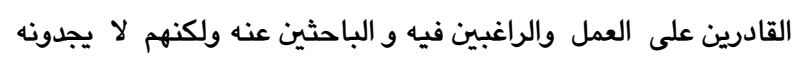
• (جودة وعيسى، 2010 : 64) .

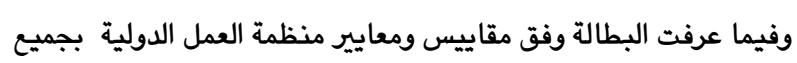
الأفراد الذين ينتمون لسن العمل (15 سنة فأكثر) ولم يعملوا أبدا

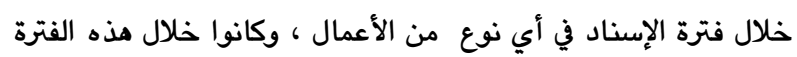

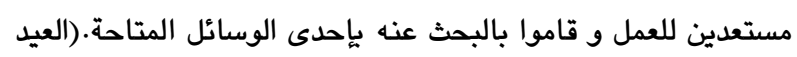

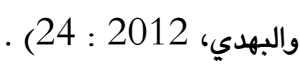
ويعرف الاقتصاديون البطالة بائض عرض العمل عن الطلب

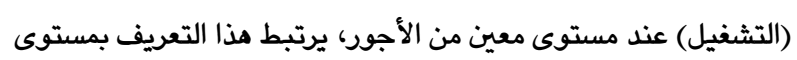

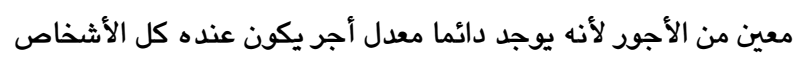

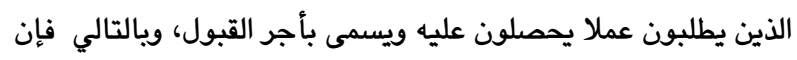

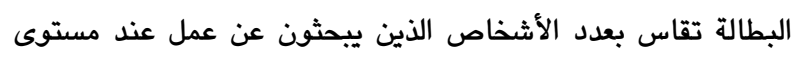

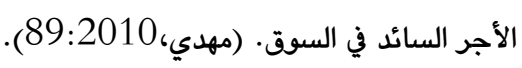

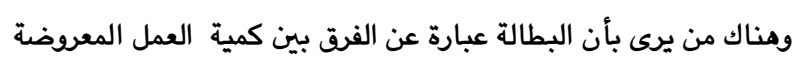

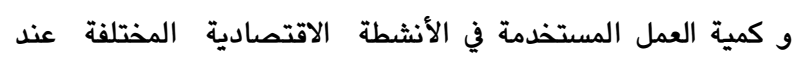
مستويات الأجر وظروف العمل السائدة في السوق · (البريفكاني وآخرون،218:2010). في حين يرى آخرون بأن البطالة يشير إلى أولئك العاطلين الذين يدخلون

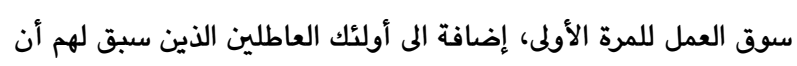

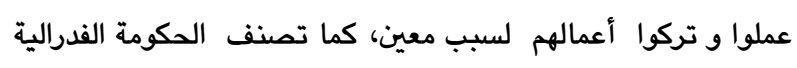

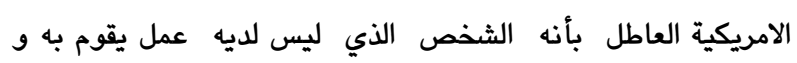

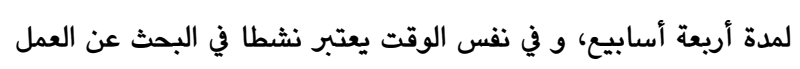
و قادرا على ادائه حال توفره. (البكر، 154:2009).

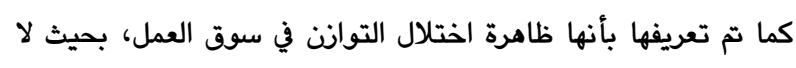

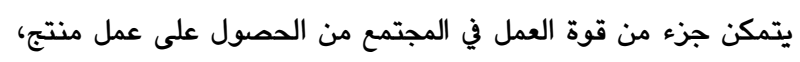

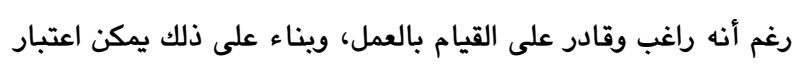

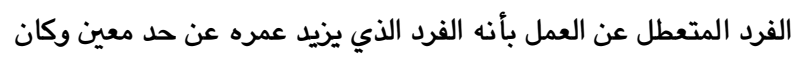

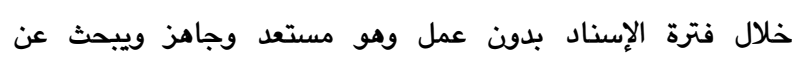
العمل.(حسين وسعيد، 327:2004) وتم تعريفها أيضا بأنها عدم وجود فرصة عمل لمن يرغب في العمل

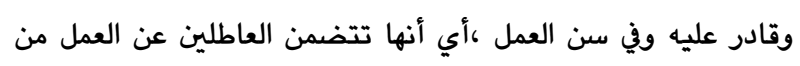

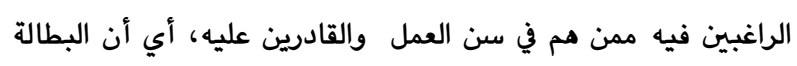

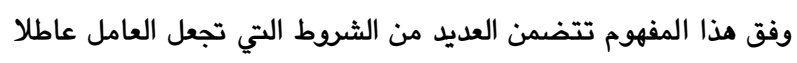
عن العمل وهي : (خلف، 2007: 335 -336) 1. أن يكون في سن العمل وهذا يعني استبعاد من هم خارج سن إنس العمل. - الم. 2. أن يكون العامل قادراً على أداء العمل، أي أن لا يكون مريضا

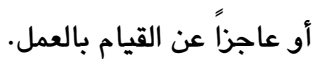


العمالة إلى بطالة كبيرة في حال عدم امتصاص قوى الطلب على العمل

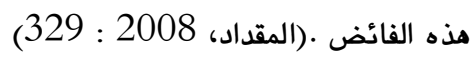
: 5 يعرف التضخم بأنه الارتفاع المستمر والمتواصل في المستوى العام للأسعار، ولا يقصد بالتضخم الارتفاع في سعر سلعة معينة واحدة بل الزيادة في المستوى العام للأسعار لكل السلع وعلى نحو مستمر . (Delong , 2002 : 327) إن التضخم والبطالة ظاهرتان سيئتان ومن بين الرواد الأوائل الذين درسوا العلاقة بينهما هو الاقتصادي الانكليزي(A. W. Philips) الذي قام برسم منحنى بياني عرفت فيما بعد بمنحنى فيليبس لتحليل العلاقة بين معدلات البطالة وتغيرات الأجور في بريطانيا للمدة 1861 - 1957 وتوصل إلى منحنى على شكل حرف L الذي يوحي بوجود علاقة عكسية بين معدلات الأجور والبطالة ثم وسع الباحثون نطاق الدراسة ليشمل العلاقة بين تغيرات الأسعار ومعدلات البطالة، ويفسر منحنى فيليبس العلاقة العكسية بين معدلات الأجود والبطالة على النحو

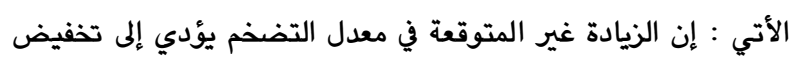
الأجور الحقيقية ويؤدي إلى زيادة الطلب على العمل وتخفيض معدل البطالة . (عبد الرحمن وعريقات، 2004 : 156 - 157) (عبد ويدئ الرحمن، 2002 : 20 (عبد البط يعرف سعر الفائدة الحقيقي بأنه عبارة عن القوة الشرائية للفائدة الاسمية، بمعنى سعر الفائدة الاسمي بعد أخذ ارتفاع الأسعار (التضخم)

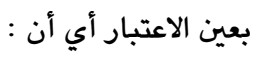
سعر الفائدة الحقيقي = سعر الفائدة الاسمي - معدل التضخم ويعرف أيضا بأنه سعر فائدة القرض الذي يتم تعديله بسبب التضخم كما يقيسه معامل انكماش الناتج المحلي، ولارتفاع سعر الفائدة الحقيقي تأثير سلبي على الاستثمار المحلي المباشر لسببين هما : 1. ارتفاع سعر الفائدة الحقيقي يرفع التكلفة الحقيقية للائتمان . 2. ارتفاع سعر الفائدة الحقيقي يقلل من القيمة الحقيقية للأصول المستثمرة، ويجعلها قليلة بالمقارنة مع السعر السائد في السوق مما

يقلل الدافع على الاستثمار. (حسين وعبادي 2013 : 432) ويالمقابل تتمثل الأهمية الاقتصادية لانخفاض سعر الفائدة الحقيقي إلى تشجيع الاستثمار وزيادة الإنتاج والإنتاجية مما يؤدي إلى زيادة الدخل القومي وارتفاع متوسط نصيب الفرد منه ويالتالي تحسين مستوى معيشة المواطنين، وتوفير فرص العمل في الاقتصاد ويالتالي تخفيض معدلات البطالة (عثامنة والزعبي، 2009 : 377) ويذلك فان انخفاض سعر الفائدة الحقيقي يشجع المستثمرين على الاستثمار وتزداد العمالة وتنخفض البطالة تبعا لذلك، أي أن العلاقة طردية بين سعر الفائدة الحقيقي ومعدل البطالة .
نفس الوقت فان العمال العاطلين عن العمل والباحثين عنه لن يقتنعوا بأنه حصل بالفعل انخفاض في الطلب على خدماتهم لذا فإنهم لن يقبلوا بالأعمال التي تعرض عليهم بأجور أقل اعتقاداً منهم بأنهم سيجدون عملا أفضل وهذا يؤدي إلى بقائهم عاطلين عن العمل لفترة طويلة .

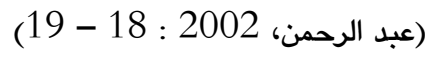
2. تعد المساعدات الخارجية مصدرا" من مصادر الإيرادات العامة التي

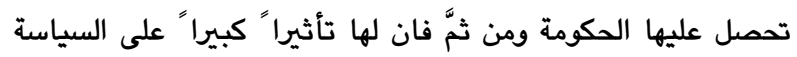
الإنفاقية سواء كانت جارية أم استثمارية ويالتالي فان التوسع في السياسة الانفاقية من قبل الحكومة يؤدي إلى زيادة الإنتاج والذي يتطلب زيادة مستوى التوظف وانخفاض معدل البطالة، وهذا يعني أن العلاقة بين المساعدات الخارجية والبطالة هي علاقة عكسية. (خليل واللوزي، (294:1999

3. النفقات الاستثمارية الحكومية : التحة أن النفقات الاستثمارية لها اثرا" إيجابيا” على الأنشطة الاقتصادية

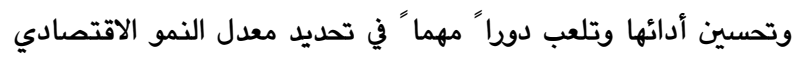
طويل الأجل ( 2 : 2002 (Hosoya , 2002 ويمثل تضحية بنقد اليوم على أمل الحصول على منافعه مستقبلا"

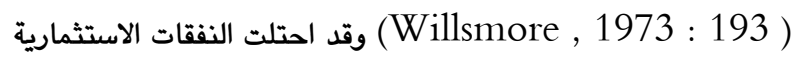
أهمية خاصة لعلاقتها الوثيقة بنمو الدخل القومي حيث يعتبر الأخير

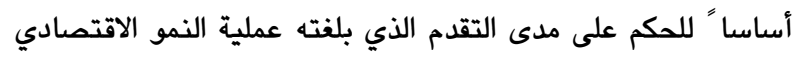
والاجتماعي في بلد ما (الكرخي، 2001، 109 ملئ ) . بناءا"على ذلك فان الإنفاق الاستثماري يعتبر المحرك الرئيسي الذي من خلاله يمكن للحكومة خلق وظائف واستقطاب اكبر عدد من العمال ويالتالي تمتص البطالة أو تخفف من حدتها، إن زيادة الإنفاق الاستثماري الحكومي يؤدي إلى زيادة الطلب الكلي ويترتب على ذلك زيادة الإنتاج والذي يتطلب زيادة مستوى التوظف وانخفاض معدل البطالة، وهذا يعني أن العلاقة بين الإنفاق الحكومي والبطالة علاقة عكسية، فكلما زادت الحكومة من حجم إنفاقها، كلما انخفضت معدلات البطالة والعكس صحيع ·(الاسطل، 2014 : 66) : 4. يؤمن النمو السكاني زيادة في عرض العمل والنمو السكاني المرتفع الذي تواكبه زيـادة في أعداد القـوة البشرية وارتفاع أعداد الداخلين إلي سوق العمل، قد يؤدي إلى ارتفاع نسبة البطالة والإضرار بعمليـة

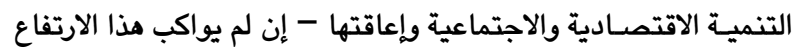
في السكان نمو اقتصادي مناسب - ونقص في الطلب على اليد العاملة، وارتفاع في نسبة البطالة، وإعاقة لعملية التنمية، كونه يؤثر في كفاية السكان من المواد الغذائية، السكن، التعليم والخدمات الصحية وغيرما، ويشكل عام يمكننا إجمال تلك العلاقة في كون النمو السكاني الكبير يرافقه عمالة كبيرة وفائضة، في أغلب الأحيان تتحول هذه 
1\% مع بقاء العوامل الأخرى على حالها، وأرجع ذلك إلى تباطؤ النمو الاقتصادي، نظرا" لقلة رغبة الشركات في استثمار أموالها في شراء المعدات الجديدة أثناء فترات التصنيع التي تمثل العمر الافتراضي

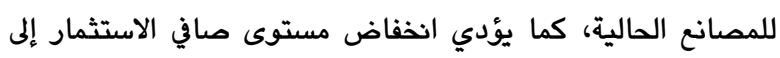
إضافة أقل لرأس المال، ومن ثم تناقص نمو القدرة الإنتاجية، ويمرود الوقت يفقد العاطلون عن العمل دورياً ما لديهم من مهارات، وشعور بالاعتزاز بالنفس، كما يفتقرون إلى وجود دافع أو حافز كاف، مما يترتب على ذلك الإضرار بقدراتهم الإنتاجية، التي غالباً يستحيل إستعادتها حتى لو تمكنوا من العثور على وظيفة جديدة. (العيد وبهدي،

(26: 2012

\section{4. مسارات ومحددات البطالة في الأردن}

يتضمن هذا المبحث تحليل سلوك واتجاه البطالة بين الذكور والإناث في الأردن خلال المدة (1991 - 2013)، وتوصيف متغيرات الدراسة المتمثلة بـ (معدل البطالة، عرض النقد، المساعدات الخارجية، النفقات الاستثمارية، معدل نمو السكان، معدل التضخم، سعر الفائدة الحقيقي، إجمالي تكوين رأس المال الثابت، الناتج المحلي الإجمالي) باستخدام

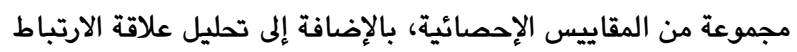
والأثر بين المتغير المعتمد (معدل البطالة) ومجموعة من المتغيرات

المستقلة.

1.4. اتجاهات البطالة لدى الذكور والإناث في الأردن: يبين الجدول (1) معدل البطالة لدى الذكور كنسبة مئوية من إجمالي

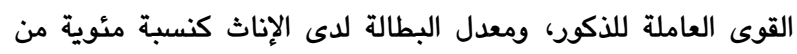

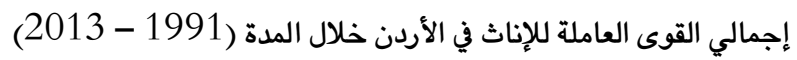

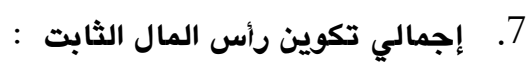

يشير إجمالي التكوين الرأسمالي الثابت إلى إجمالي الاستثمارات في

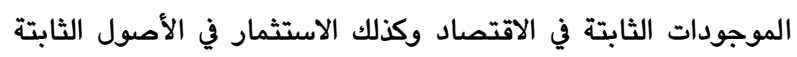
الممولة من الأموال التي جُمعت عن طريق سوق رأس المال، إن إدخال التحسينات في تكوين رأس المال ومتابعتها والإصلاحات الاقتصادية وفسح المجال إمام القطاع الخاص وتشجيعها عن طريق الحكومة لها أثار ايجابية لأنه يؤدي إلى تدقيق الكفاءة وإنتاجية في العمل والاستخدام الأمثل للموارد الاقتصادية وزيادة مستوى التشغيل وتوليد معدل ئلي تضخم منخفض وتعزيز النمو الاقتصادي ويالتالي الدد من البطالة (Ayemere \& et al. , 2014 : 160)

$$
\text { 8. الناتج المحلي الإجمالي: }
$$
يعرف الناتج المحلي الإجمالي بأنه القيمة السوقية لجميع السلع والخدمات النهائية المنتجة في بلد ما خلال فترة معينة من الزمن وهناك علاقة بين الناتج (Rauch \& Chi , 2010 : 104) المحلي الإجمالي ومعدل البطالة وتنبثق من فكرة تفترض أن البطالة

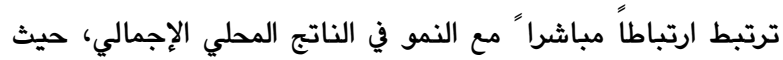
يعتبر نمو الناتج المحلي الإجمالي أحد المتغيرات الذي يفترض به أن يؤدي إلى التخفيف من حدة البطالة داخل الاقتصاد القومي . وقد اكتشف الباحث الأمريكي Arthur Okun في عام 1962 وجود علاقة عكسية مابين الناتج المحلي الإجمالي ومعدل البطالة، عندما استخدم بيانات ريع سنوية للاقتصاد الأمريكي خلال الفترة 1947 - 1957 وتوصل إلى أن انخفاض معدل الناتج المحلي

\begin{tabular}{|c|c|c|}
\hline معدل البطالة لدى الإناث \% & معدل البطالة لدى الذكور \% & السنوات \\
\hline 23.90 & 14.30 & 1991 \\
\hline 30.40 & 15.80 & 1992 \\
\hline 36.80 & 17.30 & 1993 \\
\hline 34.00 & 16.00 & 1994 \\
\hline 27.00 & 12.70 & 1995 \\
\hline 25.20 & 11.90 & 1996 \\
\hline 24.90 & 11.00 & 1997 \\
\hline 22.10 & 12.30 & 1998 \\
\hline 25.10 & 11.00 & 1999 \\
\hline 21.90 & 12.30 & 2000 \\
\hline 23.40 & 14.60 & 2001 \\
\hline 24.50 & 14.70 & 2002 \\
\hline 23.10 & 14.10 & 2003 \\
\hline 17.10 & 11.70 & 2004 \\
\hline 27.00 & 12.80 & 2005 \\
\hline 25.90 & 11.90 & 2006 \\
\hline 26.70 & 10.20 & 2007 \\
\hline 25.50 & 10.00 & 2008 \\
\hline
\end{tabular}
الإجمالي بنسبة 3\% سوف يؤدي إلى زيادة في معدل البطالة بنسبة 


\begin{tabular}{ccc}
\hline 25.00 & 10.20 & 2009 \\
\hline 22.80 & 10.20 & 2010 \\
\hline 22.00 & 10.90 & 2011 \\
\hline 21.00 & 10.30 & 2012 \\
\hline 22.10 & 10.50 & 2013 \\
\hline 23 & 23 & $\mathrm{~N}$ \\
\hline 25.10 & 12.47 & Mean \\
\hline 36.80 & 17.30 & Maximum \\
\hline 17.10 & 10.00 & Minimum \\
\hline 19.70 & 7.30 & Range \\
\hline 4.20 & 2.14 & Std. \\
& & Deviation \\
\hline
\end{tabular}

http://data.albankaldawli.org المصدر: الجدول من إعداد الباحث بالاعتماد على بيانات البنك الدولي على الموقع

(3810.1) مليون دينار عام 1991 ويلغ المدى بين أعلى وأقل قيمة

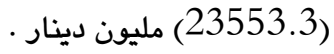

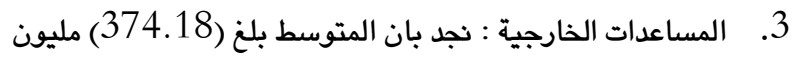
دينار بانحراف معياري (258.06) وقد بلغت أعلى قيمة (1215)

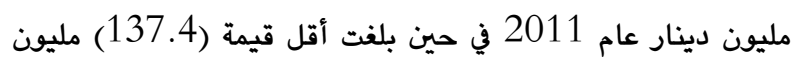

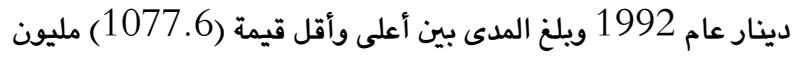

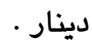
4. النفقات الاستثمارية : نجد بان المتوسط بلغ (3011.79) • (611) مليون

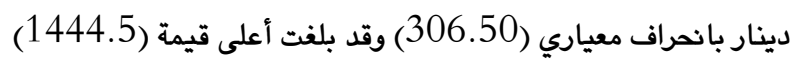
مليون دينار عام 2009 في حين كانت أقل قيمة (292.3) مليون

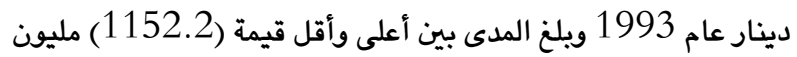

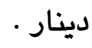

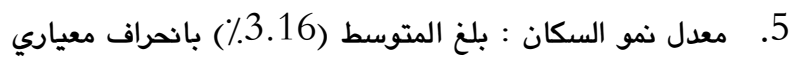

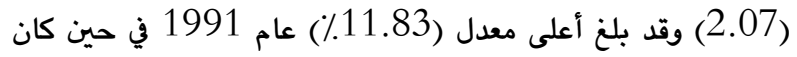
أقل معدل (1.83٪) عام 1999 ويلغ المدى بين أعلى وأقل معدل . (\%10)

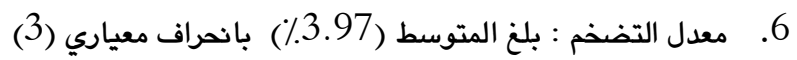

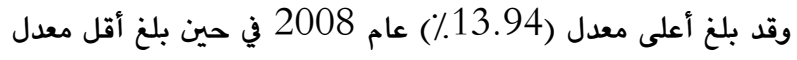

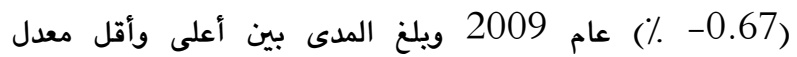
. (\%14.61) 7. سعر الفائدة الحقيقي : نجد بان المتوسط بلغ (54.54٪)

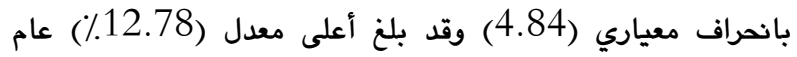

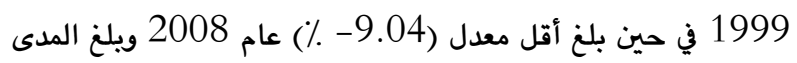
بين أعلى وأقل معدل (21.82٪) .
وتظهر معدلات البطالة بأنها مرتفعة لدى الإناث مقارنة مع الذكور حيث بلغ المتوسط الحسابي لمعدلات البطالة لدى الإناث (25.10\%) بانحراف معياري (4.20) في حين بلغ المتوسط لدى الذكور

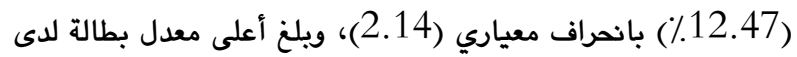

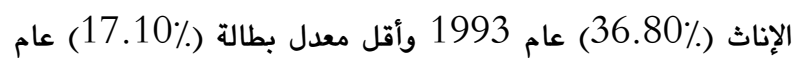

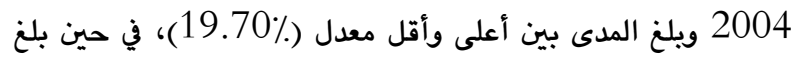

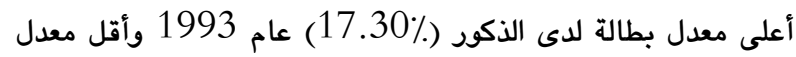
بطالة (10\%) عام 2008 ويلغ المدى بين أعلى وأقل معدل .$(\% .7 .30)$

\section{4 توصيف متغيرات الدراسة}

يبين الجدول (2) استخدام مجموعة من المقاييس الإحصائية المتمثلة بـ (المتوسط الحسابي، الانحراف المعياري، أعلى قيمة، أقل قيمة، المدى) والتي تسهم في التعرف على طبيعة البيانات المستخدمة في الاني

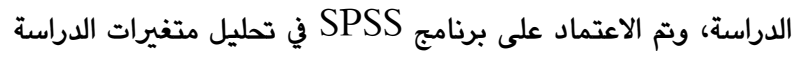

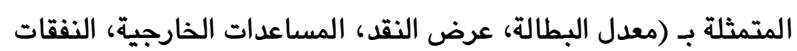

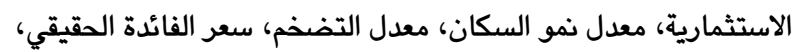

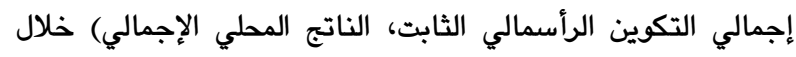
المدة (1991 - 2013) وكما يلي: 1. معدل البطالة : نجد بان المتوسط بلغ (14.35\%) بلغ (14) بانحراف

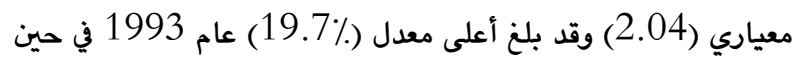
بلغ أقل معدل (12.2\%) عام 2012 ويلغ المدى بين أعلى وأقل معدل • (\%7.5)

2. عرض النقد : نجد بان المتوسط بلغ (11694.57) مليون

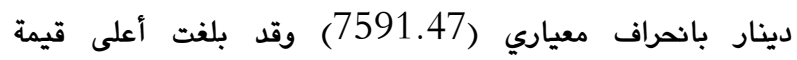
(27363.4) مليون دينار عام 2013 في حين بلغ أقل قيمة 
الجدول (2): توصيف بيانات الدراسة باستخدام مجموعة من المقاييس الإحصائية

\begin{tabular}{|c|c|c|c|c|c|c|c|c|c|}
\hline الإجمالي المبالغ & $\begin{array}{c}\text { التألكابت المبالين } \\
\text { الماليالين } \\
\text { المالين }\end{array}$ & $\begin{array}{c}\text { سعر الفائدة } \\
\text { الحقيقي () }\end{array}$ & $\begin{array}{l}\text { التضخد } \\
\text { (\%) }\end{array}$ & $\begin{array}{c}\text { معدل نمو } \\
\text { السكان } \\
\text { (\%) }\end{array}$ & الاستثمارية & الخالمالماعداتية & 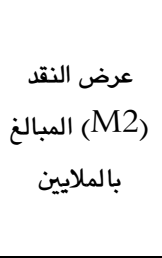 & $\begin{array}{c}\text { البطالة } \\
\text { (\%) }\end{array}$ & السنوات \\
\hline 2958.00 & 678.00 & 4.90 & 8.28 & 11.83 & 333.10 & 230.20 & 3810.10 & 15.40 & 1991 \\
\hline 3610.64 & 1049.20 & 7.10 & 3.91 & 5.30 & 352.70 & 137.40 & 4266.90 & 17.50 & 1992 \\
\hline 3884.29 & 1303.50 & 7.21 & 3.33 & 4.63 & 292.30 & 163.10 & 4481.80 & 19.70 & 1993 \\
\hline 4358.31 & 1391.00 & 3.34 & 3.60 & 3.97 & 376.20 & 175.50 & 4841.50 & 18.30 & 1994 \\
\hline 4714.59 & 1395.00 & 8.62 & 2.24 & 3.30 & 384.40 & 182.80 & 5159.80 & 14.60 & 1995 \\
\hline 4912.21 & 1444.90 & 9.00 & 6.59 & 3.10 & 410.20 & 247.00 & 5175.30 & 13.70 & 1996 \\
\hline 5136.28 & 1324.90 & 10.88 & 2.99 & 3.10 & 427.20 & 205.00 & 5576.60 & 12.90 & 1997 \\
\hline 5608.63 & 1187.50 & 6.22 & 3.10 & 3.09 & 443.20 & 172.20 & 6026.30 & 13.70 & 1998 \\
\hline 5776.57 & 1352.68 & 12.78 & 0.58 & 1.83 & 396.40 & 198.50 & 6747.60 & 12.90 & 1999 \\
\hline 5996.67 & 1266.58 & 12.26 & 0.68 & 2.48 & 335.80 & 240.20 & 7434.70 & 13.70 & 2000 \\
\hline 6362.00 & 1235.79 & 10.08 & 1.75 & 2.50 & 403.80 & 249.40 & 7866.10 & 15.80 & 2001 \\
\hline 6792.51 & 1287.34 & 9.17 & 1.86 & 2.46 & 438.70 & 266.60 & 8419.10 & 16.20 & 2002 \\
\hline 7227.04 & 1490.81 & 7.00 & 2.38 & 2.50 & 466.90 & 687.70 & 9465.70 & 15.40 & 2003 \\
\hline 8087.96 & 2005.41 & 5.02 & 2.56 & 2.44 & 621.00 & 667.00 & 10571.40 & 12.40 & 2004 \\
\hline 8925.36 & 2733.74 & 5.47 & 3.52 & 2.29 & 634.60 & 501.00 & 12364.00 & 14.90 & 2005 \\
\hline 10675.37 & 2717.10 & -2.24 & 6.26 & 2.31 & 794.10 & 304.50 & 14109.70 & 14.00 & 2006 \\
\hline 12131.42 & 3334.10 & 3.45 & 4.70 & 2.26 & 842.60 & 343.40 & 15606.90 & 13.10 & 2007 \\
\hline 15593.41 & 4342.90 & -9.04 & 13.94 & 2.21 & 958.50 & 718.30 & 18304.30 & 12.70 & 2008 \\
\hline 16911.01 & 4254.20 & 6.25 & -0.67 & 2.23 & 1444.50 & 333.40 & 20013.30 & 12.90 & 2009 \\
\hline 18762.02 & 4313.13 & 0.56 & 5.06 & 2.21 & 961.40 & 401.70 & 22306.70 & 12.50 & 2010 \\
\hline 20476.59 & 5018.42 & 2.16 & 4.38 & 2.23 & 1057.10 & 1215.00 & 24118.90 & 12.90 & 2011 \\
\hline 21965.47 & 5714.40 & 4.10 & 4.65 & 2.22 & 675.40 & 327.20 & 24945.10 & 12.20 & 2012 \\
\hline 23851.63 & 6492.98 & 3.23 & 5.59 & 2.23 & 1021.00 & 639.10 & 27363.40 & 12.60 & 2013 \\
\hline 23 & 23 & 23 & 23 & 23 & 23 & 23 & 23 & 23 & $\mathrm{~N}$ \\
\hline 9770.35 & 2492.76 & 5.54 & 3.97 & 3.16 & 611.79 & 374.18 & 11694.57 & 14.35 & Mean \\
\hline 2958 & 678 & -9.04 & -0.67 & 1.83 & 292.3 & 137.4 & 3810.1 & 12.2 & Minimum \\
\hline 23851.63 & 6492.98 & 12.78 & 13.94 & 11.83 & 1444.5 & 1215 & 27363.4 & 19.7 & Maximum \\
\hline 20893.63 & 5814.98 & 21.82 & 14.61 & 10.00 & 1152.2 & 1077.6 & 23553.3 & 7.5 & Range \\
\hline 6504.19 & 1703.86 & 4.84 & 3.00 & 2.07 & 306.50 & 258.06 & 7591.47 & 2.04 & Std. Deviation \\
\hline
\end{tabular}

http://data.albankaldawli.org المصدر: الجدول من إعداد الباحث بالاعتماد على بيانات البنك الدولي على الموقع

3.4. قياس وتقدير أثر المتغيرات المستقلة على معدل

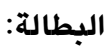

سيتم في هذا الجزء من الدراسة الوقوف على تأثير المتغيرات المستقلة

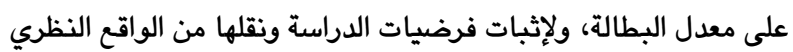

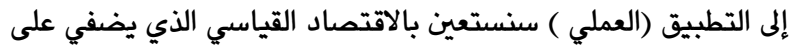

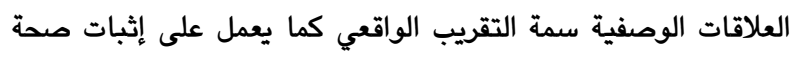
النظريات الاقتصادية أو خطئها ومن ثمَّ فإن استخدام أسلوب التحليل

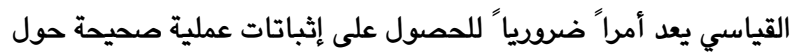
الظاهرة المدروسة، وكذلك للتأكد من صحة الفرضيات والعلاقات

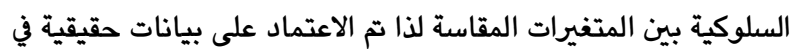

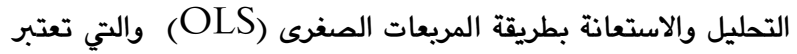

إجمالي تكوين رأس المال الثابت : نجد بان المتوسط بلغ

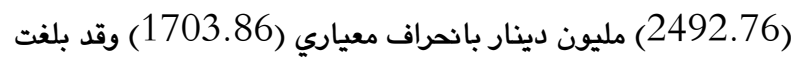
أعلى قيمة (6492.98) مليون دينار عام 2013 في حين بلغ أقل

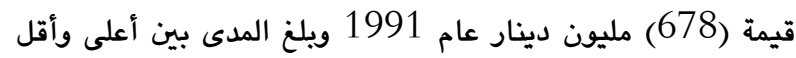
قيمة (5814.98) مليون دينار . 8. مليون دينار بانحراف معياري (6504.19) وقد بلغت أعلى قيمة

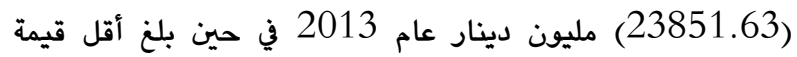

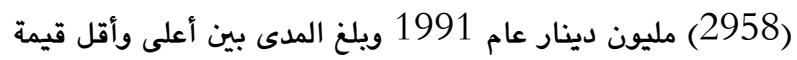

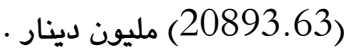


X2 المساعدات الخارجية وقد عبرنا عنه بالأرقام المطلقة ويالأسعار الجارية. X3 النفقات الاستثمارية الحكومية وقد عبرنا عنه بالأرقام المطلقة

$$
\text { ويالأسعار الجارية. }
$$

X4

X5 : معدل التضخم وقد عبرنا عنه بنسبة مئوية.

X6 سعر الفائدة الحقيقي وقد عبرنا عنه بنسبة مئوية.

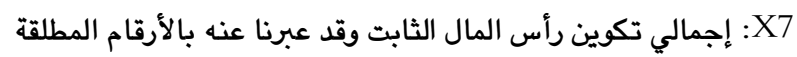

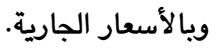

X8 الناتج المحلي الإجمالي وقد عبرنا عنه بالأرقام المطلقة ويالأسعار X8 الجارية.

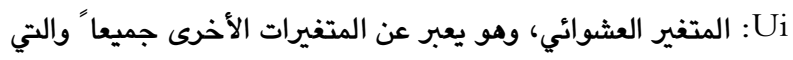
يمكن أن تؤثر على مستوى البطالة والتي لم يتطرق إليها الباحث، إذ أن لكل ظاهرة أو متغير مدروس العديد من العوامل المختلفة والتي تؤثر فيها بشتى الطرق، ولذا فقد يتناول المهتم بالموضوع أحد تلك العوامل

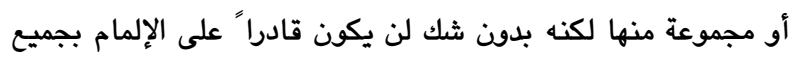

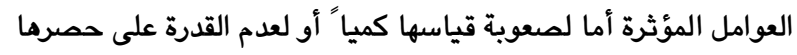

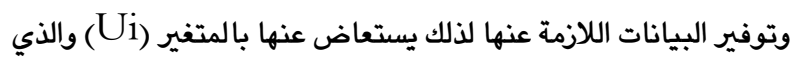

$$
\text { يعبر عن تلك المتغيرات جميعاً. }
$$

2. عرض وتحليل نتائج تقدير النموذج الاقتصادي القياسي

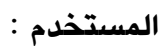

بعد إدخال البيا نات في برنامج SPSS ظهرت ذتائج تقدير كل من النموذج الخطي ونموذج الجذر التربيعي (بعد أجراء ســلســلة من

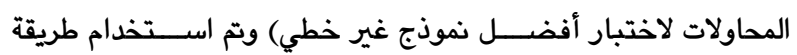

$$
\text { الانحدار التدريجي Stepwise لإظهار النتائج وكما يلي : }
$$

نتائج تقدير النموذج الخطي لمعدل البطالة في الاردن خلال

$$
\text { المدة (1991 - 2013) }
$$

من أفضل الطرق لتقدير النماذج، واتساقا" مع ذلك تم الاعتماد على النموذج الخطي والنموذج غير الخطي وياستخدام عدة صيغ تم التوصل إلى أفضل صيغة وهي الصيغة الجذرية لطرفي النموذج • 1

يتكون النموذج من معادلة انحدار متعدد يتضمن مجموعة من المتغيرات المستقلة وهي (عرض النقد، المساعدات الخارجية، النفقات الاستثمارية الحكومية، معدل نمو السكان، معدل التضخم، سعر الفائدة الحقيقي،إجمالي تكوين رأس المال الثابت، الناتج المحلي الإجمالي) ومتغير معتمد واحد هو (معدل البطالة)، كما أن النموذج يتضمن المتغير العشوائي والذي يوضع بجانب المتغيرات المستقلة وهو يمثل جميع المتغيرات الأخرى التي تؤثر على معدل البطالة والتي لم يتم التطرق إليها . ويمكن توصيف الدالة بالشكل الأتي : $\mathrm{Y}=\mathrm{F}(\mathrm{X} 1, \mathrm{X} 2, \mathrm{X} 3, \mathrm{X} 4, \mathrm{X} 5, \mathrm{X} 6, \mathrm{X} 7, \mathrm{X} 8)$ وسيتم استخدام الصيخ القياسية الآتية : الصيغة الأولى : النموذج الخطي $\mathrm{Y}=\mathrm{b} 0+\mathrm{b} 1 \mathrm{X} 1+\mathrm{b} 2 \mathrm{X} 2+\mathrm{b} 3 \mathrm{X} 3+\mathrm{b} 4 \mathrm{X} 4+\mathrm{b} 5$ $\mathrm{X} 5+\mathrm{b} 6 \mathrm{X} 6+\mathrm{b} 7 \mathrm{X} 7+\mathrm{b} 8 \mathrm{X} 8+\mathrm{Ui}$

$$
\text { الصيغة الثانية : النموذج غير الخطي (الجذر الربيعي) }
$$
$\sqrt{y}=\mathrm{b} 0+\mathrm{b} 1 \sqrt{x 1}+\mathrm{b} 2 \sqrt{x 2}+\mathrm{b} 3 \sqrt{x 3}+\mathrm{b} 4$ $\sqrt{x 4}+\mathrm{b} 5 \sqrt{x 5}+\mathrm{b} 6 \sqrt{x 6}+\mathrm{b} 7 \sqrt{x 7}+\mathrm{b} 8 \sqrt{x 8}+$ $\mathrm{Ui} \square$

\begin{tabular}{|c|c|c|c|c|c|c|c|c|}
\hline \multicolumn{9}{|c|}{ Model Summary ${ }^{b}$} \\
\hline Model & $\mathrm{R}$ & R Square & \multicolumn{2}{|c|}{ Adjusted R Square } & \multicolumn{3}{|c|}{$\begin{array}{l}\text { Std. Error of the } \\
\text { Estimate }\end{array}$} & Durbin-Watson \\
\hline 1 & $.605^{\mathrm{a}}$ & .367 & \multicolumn{2}{|c|}{.336} & \multicolumn{3}{|c|}{1.65898} & .885 \\
\hline \multicolumn{9}{|c|}{ a. Predictors: (Constant), $\mathrm{x} 8$} \\
\hline \multicolumn{9}{|c|}{ b. Dependent Variable: y } \\
\hline \multicolumn{9}{|c|}{ الجدول (4) } \\
\hline & \multicolumn{7}{|c|}{ ANOVA $^{a}$} & \\
\hline & \multicolumn{2}{|r|}{ Model } & $\begin{array}{l}\text { Sum of } \\
\text { Squares }\end{array}$ & df & & $\mathrm{F}$ & Sig. & \\
\hline & \multirow{3}{*}{1} & Regression & 33.441 & 1 & & 12.150 & $.002^{\mathrm{b}}$ & \\
\hline & & Residual & 57.797 & 21 & & & & \\
\hline & & Total & 91.237 & 22 & & & & \\
\hline & \multicolumn{7}{|c|}{ a. Dependent Variable: y } & \\
\hline & \multicolumn{7}{|c|}{ b. Predictors: (Constant), $\mathrm{x} 8$} & \\
\hline
\end{tabular}

$$
\text { إذ يعبر : }
$$

معدل البطالة وهو يمثل المتغير المعتمد (المستجيب) وقد عبرنا :Y

عنه بنسبة مئوية.

X1 عرض النقد وقد عبرنا عنه بالأرقام المطلقة ويالأسعار الجارية.

\section{الجدول (3)}


(5) الجدول

\section{Coefficients $^{\text {a }}$}

\begin{tabular}{|c|c|c|c|c|c|c|c|c|c|}
\hline \multirow{2}{*}{\multicolumn{2}{|c|}{ Model }} & \multicolumn{3}{|c|}{ Unstandardized Coefficients } & \multirow{2}{*}{$\begin{array}{c}\text { Standardized } \\
\text { Coefficients } \\
\text { Beta }\end{array}$} & \multirow{2}{*}{$\mathrm{t}$} & \multirow{2}{*}{ Sig. } & \multicolumn{2}{|c|}{ Collinearity Statistics } \\
\hline & & \multicolumn{2}{|c|}{ B } & Std. Error & & & & Tolerance & VIF \\
\hline \multicolumn{2}{|r|}{ (Constant) } & \multicolumn{2}{|c|}{16.200} & .634 & & 25.552 & .000 & & \\
\hline \multirow{2}{*}{\multicolumn{2}{|c|}{$\mathrm{x} 8$}} & \multicolumn{2}{|c|}{.000} & .000 & $-.605-$ & $-3.486-$ & .002 & 1.000 & 1.000 \\
\hline \multicolumn{9}{|c|}{ a. Dependent Variable: $\mathrm{y}$} & \\
\hline \multicolumn{10}{|c|}{ الجدول (6) } \\
\hline \multicolumn{10}{|c|}{ Excluded Variables ${ }^{a}$} \\
\hline \multirow{2}{*}{\multicolumn{2}{|c|}{ Model }} & \multirow[t]{2}{*}{ Beta In } & \multirow[t]{2}{*}{$\mathrm{t}$} & \multirow[t]{2}{*}{ Sig. } & \multirow[t]{2}{*}{ Partial Correlation } & \multicolumn{4}{|c|}{ Collinearity Statistics } \\
\hline & & & & & & Toleranc & & VIF & $\begin{array}{l}\text { Minimum } \\
\text { Tolerance }\end{array}$ \\
\hline \multirow{7}{*}{1} & $\mathrm{x} 1$ & $-.296^{-b}$ & $-.160-$ & .875 & $-.036-$ & .009 & & 108.606 & .009 \\
\hline & $\mathrm{x} 2$ & $-.058-^{\mathrm{b}}$ & $-.259-$ & .798 & $-.058-$ & .629 & & 1.591 & .629 \\
\hline & $\mathrm{x} 3$ & $-.216-^{\mathrm{b}}$ & $-.662-$ & .516 & $\begin{array}{c}-146- \\
-1\end{array}$ & .291 & & 3.432 & .291 \\
\hline & $\mathrm{x} 4$ & $.191^{\mathrm{b}}$ & .990 & .334 & .216 & .815 & & 1.227 & .815 \\
\hline & $\mathrm{x} 5$ & $.008^{\mathrm{b}}$ & .042 & .967 & .009 & .944 & & 1.059 & .944 \\
\hline & $x 6$ & $-.158-^{\mathrm{b}}$ & $-.764-$ & .454 & $-.168-$ & .716 & & 1.396 & .716 \\
\hline & $\mathrm{x} 7$ & $1.017^{\mathrm{b}}$ & .961 & .348 & .210 & .027 & & 36.942 & .027 \\
\hline \multicolumn{10}{|c|}{ a. Dependent Variable: y } \\
\hline \multicolumn{10}{|c|}{ b. Predictors in the Model: (Constant), $x 8$} \\
\hline
\end{tabular}

ب . نتائج تقدير النموذج الغير خطي (نموذج الجذر التربيعي) لمعدل البطالة في الاردن خلال المدة (1991 - 2013) : الجدول (7)

\begin{tabular}{|c|c|c|c|c|c|c|}
\hline \multicolumn{7}{|c|}{ Model Summary $^{c}$} \\
\hline Model & $\mathrm{R}$ & R Square & \multicolumn{4}{|c|}{ Estimate } \\
\hline 1 & $.622^{\mathrm{a}}$ & .387 & \multicolumn{3}{|c|}{.21794} & \\
\hline 2 & $.747^{\mathrm{b}}$ & .558 & .506 & \multicolumn{2}{|c|}{.19051} & 1.991 \\
\hline \multirow{2}{*}{\multicolumn{7}{|c|}{ a. Predictors: (Constant), SQRTX3 }} \\
\hline \multicolumn{5}{|c|}{ b. Predictors: (Constant), SQRTX3, SQRTX6 } & & \\
\hline \multicolumn{7}{|c|}{ c. Dependent Variable: SQRTY } \\
\hline \multicolumn{7}{|c|}{ الجدول (8) } \\
\hline \multicolumn{7}{|c|}{ ANOVA $^{a}$} \\
\hline \multicolumn{2}{|r|}{ Model } & Sum of Squares & $\mathrm{df}$ & Tean Square & $\mathrm{F}$ & Sig. \\
\hline \multirow{3}{*}{1} & Regression & .541 & 1 & .541 & 11.384 & $.003^{\mathrm{b}}$ \\
\hline & Residual & .855 & 18 & .047 & & \\
\hline & Total & 1.396 & 19 & & & \\
\hline \multirow{3}{*}{2} & Regression & .779 & 2 & .389 & 10.727 & $.001^{\mathrm{c}}$ \\
\hline & Residual & .617 & 17 & .036 & & \\
\hline & Total & 1.396 & 19 & & & \\
\hline
\end{tabular}

a. Dependent Variable: SQRTY, b. Predictors: (Constant), SQRTX3, c. Predictors: (Constant), SQRTX3, SQRTX6

الجدول (9)

Coefficients ${ }^{\text {a }}$

\begin{tabular}{|c|c|c|c|c|c|c|c|}
\hline \multirow[t]{2}{*}{ Model } & \multicolumn{2}{|c|}{ Unstandardized Coefficients } & \multirow{2}{*}{$\frac{\text { Standardized Coefficients }}{\text { Beta }}$} & \multirow[t]{2}{*}{$\mathrm{t}$} & \multirow[t]{2}{*}{ Sig. } & \multicolumn{2}{|c|}{ Collinearity Statistics } \\
\hline & $\mathrm{B}$ & Std. Error & & & & Tolerance & $\overline{\mathrm{VIF}}$ \\
\hline (Constant) & 4.592 & .239 & & 19.179 & .000 & & \\
\hline SQRTX3 & $-.035-$ & .010 & $-.622-$ & $-3.374-$ & .003 & 1.000 & 1.000 \\
\hline (Constant) & 5.773 & .506 & & 11.402 & .000 & & \\
\hline SQRTX3 & $-.061-$ & .014 & $-1.094-$ & $-4.469-$ & .000 & .434 & 2.302 \\
\hline SQRTX6 & $-.235-$ & .092 & $-.627-$ & $-2.560-$ & .020 & .434 & 2.302 \\
\hline
\end{tabular}

a. Dependent Variable: SQRTY 
الجدول (10)

\section{Excluded Variables ${ }^{\text {a }}$}

\begin{tabular}{|c|c|c|c|c|c|c|c|c|}
\hline & \multirow{2}{*}{ Model } & \multirow{2}{*}{ Beta In } & \multirow{2}{*}{$\mathrm{t}$} & \multirow{2}{*}{ Sig. } & \multirow{2}{*}{ Partial Correlation } & \multicolumn{3}{|c|}{ Collinearity Statistics } \\
\hline & & & & & & Tolerance & VIF & Minimum Tolerance \\
\hline \multirow{7}{*}{1} & SQRTX8 & $-.287-\mathrm{b}$ & $-.584-$ & .567 & $-.140-$ & .147 & 6.812 & .147 \\
\hline & SQRTX7 & $.051^{\mathrm{b}}$ & .109 & .915 & .026 & .163 & 6.116 & .163 \\
\hline & SQRTX6 & $-.627-{ }^{\mathrm{b}}$ & $-2.560-$ & .020 & $-.528-$ & .434 & 2.302 & .434 \\
\hline & SQRTX5 & $.203^{\mathrm{b}}$ & 1.026 & .319 & .241 & .868 & 1.153 & .868 \\
\hline & SQRTX4 & $.236^{\mathrm{b}}$ & 1.130 & .274 & .264 & .767 & 1.304 & .767 \\
\hline & SQRTX2 & $.075^{\mathrm{b}}$ & .256 & .801 & .062 & .423 & 2.366 & .423 \\
\hline & SQRTX1 & $-.209-\mathrm{b}$ & $-.396-$ & .697 & $-.096-$ & .128 & 7.795 & .128 \\
\hline \multirow{6}{*}{2} & SQRTX8 & $-.118-^{\mathrm{c}}$ & $-.270-$ & .791 & $-.067-$ & .143 & 6.989 & .109 \\
\hline & SQRTX7 & $.083^{\mathrm{c}}$ & .203 & .842 & .051 & .163 & 6.122 & .132 \\
\hline & SQRTX5 & $-.100-^{c}$ & $-.452-$ & .658 & $-.112-$ & .553 & 1.807 & .277 \\
\hline & SQRTX4 & $-.099-^{\mathrm{c}}$ & $-.410-$ & .688 & $-.102-$ & .464 & 2.156 & .201 \\
\hline & SQRTX2 & $.186^{\mathrm{c}}$ & .731 & .475 & .180 & 411 & 2.435 & .238 \\
\hline & SQRTX1 & $-.003-^{\mathrm{c}}$ & $-.007-$ & .995 & $-.002-$ & .124 & 8.051 & .096 \\
\hline
\end{tabular}

a. Dependent Variable: SQRTY

b. Predictors in the Model: (Constant), SQRTX3

c. Predictors in the Model: (Constant), SQRTX3, SQRTX6

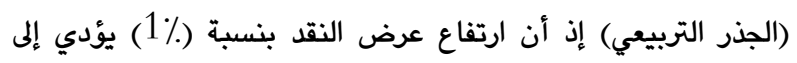

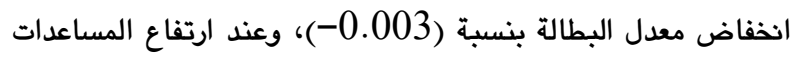
الخارجية بنسبة (1\%) يؤدي إلى ارتفاع معدل البطالة بنسبة

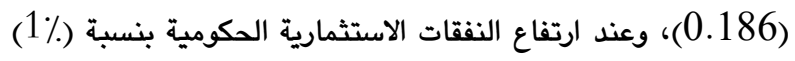
يؤدي إلى انخفاض معدل البطالة بنسبة (0.061)، وعند النفات النفارية)، وعند ارتفاع

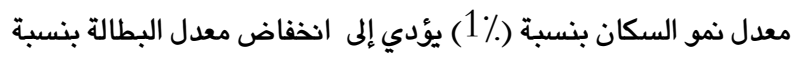

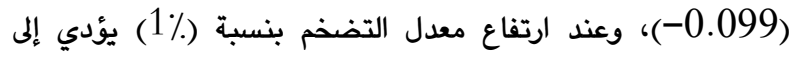
انخفاض معدل البطالة بنسبة (0.10)، وعنداع معدل، وعند ارتفاع سعر الفائدة الحقيقي بنسبة (1\%) يؤدي إلى انخفاض معدل البطالة بنسبة (0.235 -)، وعند ارتفاع إجمالي تكوين رأس المال الثابت بنسبة البطال

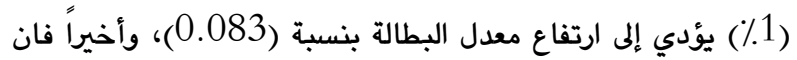

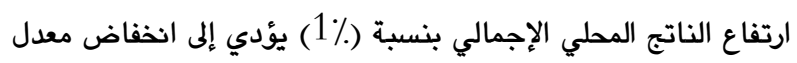

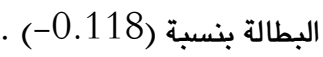
والملاحظة المهمة التي يمكن تسجيلها مو أنه عند استخدام أسلوب

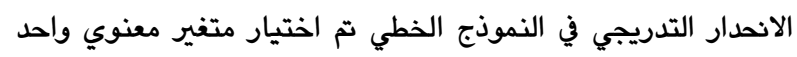

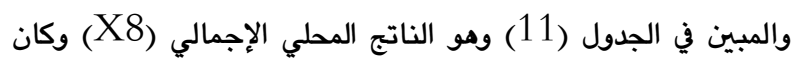

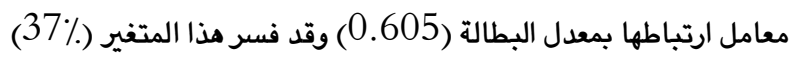

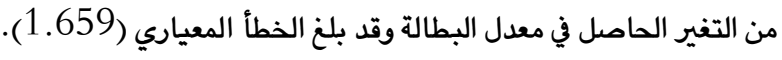
في حين عند استخدام النموذج الغير خطي (نموذج الجذر التربيعي) تم

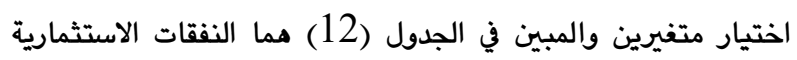

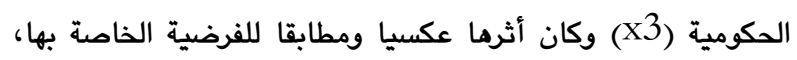

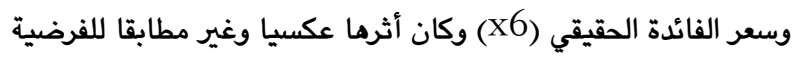
الخاصة بها وهذا يعني حتى في ظل ارتفاع سعر الفائدة الحقيقي فان المستثمرن يتوجهون إلى استثمار أموالهم وهذا يؤدي إلى انخفاض
لغرض معرفة مدى صلاحية نتائج النماذج القياسية المقدرة والمتعلقة بمعدل البطالة في الأردن، لابد من إجراء مجموعة من الاختبارات لمعرفة مدى صلاحية كل نموذج من منظور منطق النظرية الاقتصادية ومدى

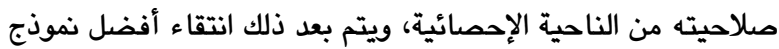
للقيام باختباره من الناحية القياسية. 1. الدراسة الاقتصادية للنموذج الخطي والنموذج غيراسية الخطي (الجذر التربيعي): التئية يتبين من النتائج المعروضة في الجدولين (5)، (6) الثبعي): أثر المتغيرات

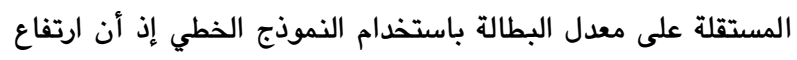

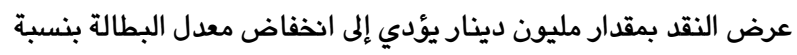
(0.296-)، وعند ارتفاع المساعدات الخارجية بمقدار مليون دينار

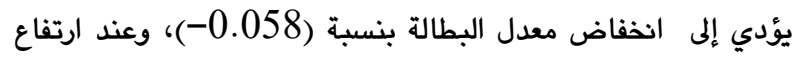

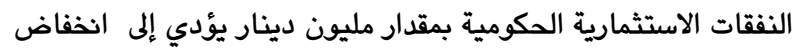
معدل البطالة بنسبة (0.216-)، وعند ارتفاع معدل نمو السكان النان

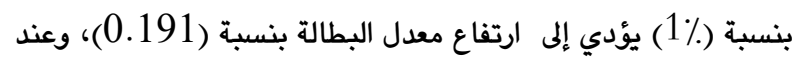

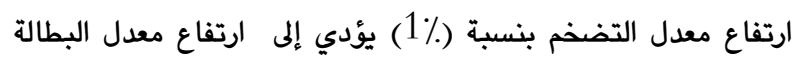
بنسبة (0.008)، وعند ارتفاع سعر الفائدة الحقيقي بنسبة (1\%)

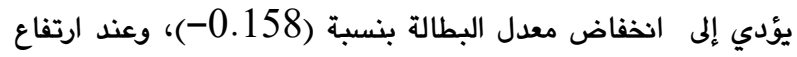

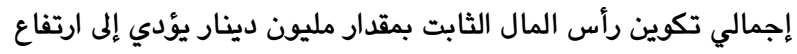

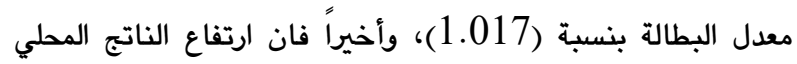

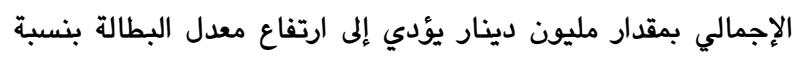
. (0.0001) كما يتبين من النتائج المعروضة في الجدولين (9)، (10) أثر نفس المتغيرات المستقلة على معدل البطالة باستخدام النموذج غير الخطي 
والمتغير X8 في النموذج، وقد ثم استبعاد المتغيرات الأخرى من النموذج لعدم معنويتها إحصائياً. ب. الدراسة الإحصائية للنموذج الغير خطي (نموذج الجذر التربيعي) : يوضح الجدول (14) نتائج اختبار (t) لنموذج الجذر التربيعي والقيم

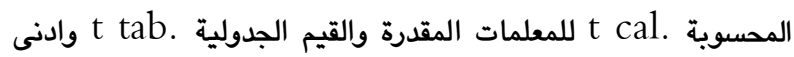

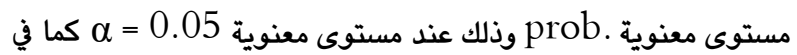

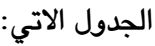

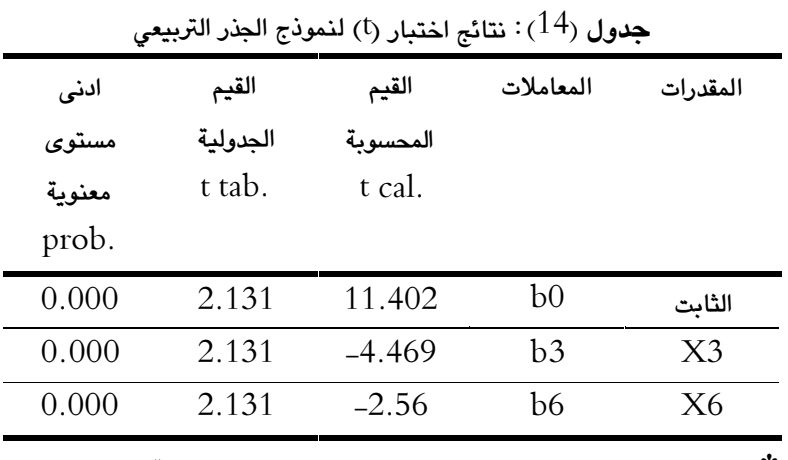

*الجدول من اعداد الباحث بالاعتماد على نتائج الحاسبة يتضح من خلال الجدول (14) معنوية الثابت (b0) وكذلك معنوية المعلمتين (b3)، (b6) حيث كانت القيم المحسوبة لتلك المعلمات أكبر من قيمتها الجدولية ويهذا سيتم رفض فرضية العدم لم0، أي أن

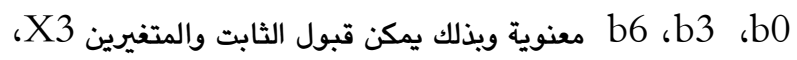

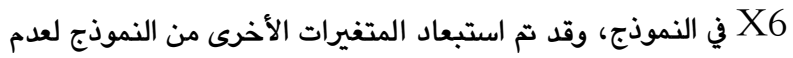
معنويتها الإحصائية . 3. اختيار النموذج الملائم : من خلال مقارنة النتائج في الجدولين (11، الإنهائ 12) وكذلك الجدولين (13، 14) نلاحظ أن النموذج الأول (الخطي)

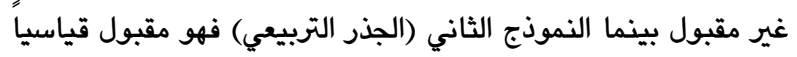
حيث أن قيمة معامل التحديد للنموذج الثاني كان أفضل من النموذج الأول (نموذج خطي 0.367 > نموذج جذر تربيعي 0.558 ) وكذلك الخطأ المعياري كان أقل (نموذج خطي 1969 المودج نموذج جذر تربيعي 0.191 ) بالإضافة إلى اختيار نموذج الجذر التربيعي لمتغيرين اثنين وهما X3، X6 في حين أن النموذج الخطي قد اختار متغير واحد فقط وهو X8 وعليه فان النموذج الذي سيتم الاخذ بها بعين الاعتبار في بقية الدراسة هو نموذج الجذر التربيعي ·
معدل البطالة، وكان معامل ارتباطهما بمعدل البطالة موجبا وقويا وينسبة (0.747) وقد فسر هذين المتغيرين (56\%) من التغير

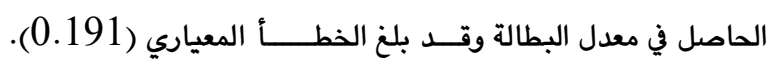
الجدول (11): نتائج تقدير النموذج الخطي لمعدل البطالة في الاردن خلال

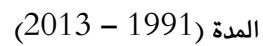

\begin{tabular}{|c|c|c|c|}
\hline المتغيرات التي & $\begin{array}{c}\text { الارتباط Re } \\
\text { R }\end{array}$ & التحديد & الخطأ المعياري \\
\hline X 8 & 0.605 & 0.367 & 1.659 \\
\hline
\end{tabular}

الجدول (12): نتائج تقدير النموذج الغير خطي (نموذج الجذر التربيعي) لمعدل البطالة في الاردن خلال المدة (1991 - 2013)

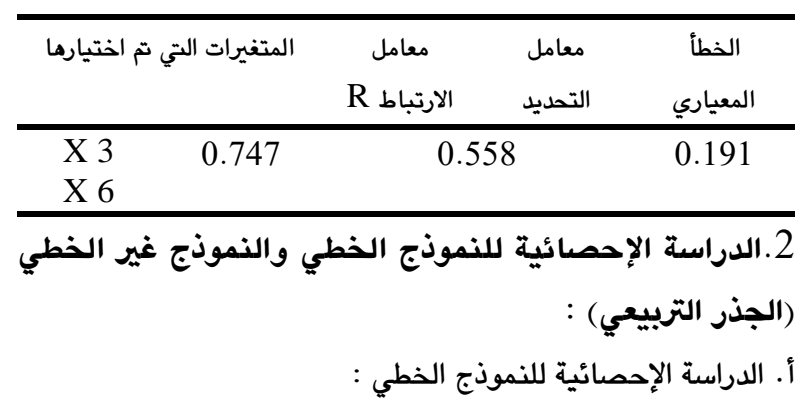
اختبار معنوية المعالم : تستخدم إحصائية ستودنت لتقييم معنوية معالم النموذج ويتم تقييم تأثير المتغيرات المستقلة على المتغير المعتمد باختبار الفرضيات الخاصة بالمعلمات المقدرة على النحو

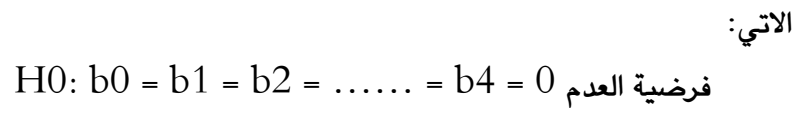
H1: b0 الفرضية البديلة يمكن توضيح نتائج اختبار (t) للنموذج الخطي من خلال الجدول (13) الذي توضح من خلاله القيم المحسوية .t cal للمعلمات المقدرة والقيم الجدولية .t tab وأدنى مستوى معنوية .prob وذلك عند مستوى معنوية $0.05=0$. (t) t tab. نستخرجها من الجدول الخاص بـ القيمة الجدولية

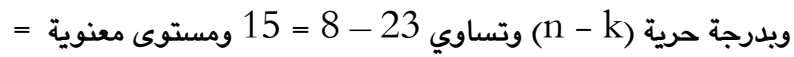

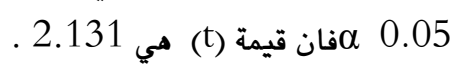
وياستخدام أسلوب الانحدار التدريجي حصلنا على النتائج الآتية :

\begin{tabular}{|c|c|c|c|c|}
\hline $\begin{array}{l}\text { prob. معنىية مستوى } \\
\text { prob }\end{array}$ & $\begin{array}{c}\text { القيم الجدولية } \\
\text { t tab. }\end{array}$ & $\begin{array}{c}\text { القيم المحسوية } \\
\text { t cal. }\end{array}$ & المعاملات & رات \\
\hline 0.000 & 2.131 & 25.552 & b0 & الثاب \\
\hline 0.002 & 2.131 & -3.486 & $\mathrm{~b} 8$ & X8 \\
\hline
\end{tabular}

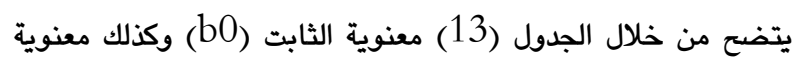
المعلمة الثامنة (b8) حيث كانت القيم المحسوية لكليها أكبر من القيم الجدولية وبهذا سيتم رفض فرضية العدم HO، ويتم قبول الثابت 


\begin{tabular}{|c|c|c|}
\hline VIF & Tolerance & المتغيرات \\
\hline 2.302 & 0.434 & X3 \\
\hline 2.302 & 0.434 & X6 \\
\hline
\end{tabular}

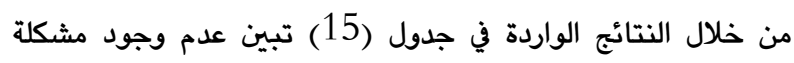

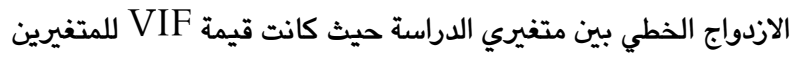

$$
\text { أقل من خمسة . }
$$

ب. اختبار الارتباط الذاتي للأخطاء : سيتم الاعتماد على اختبار

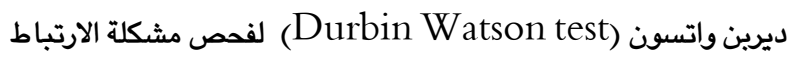
الذاتي للأخطاء باستخدام برنامج spss، إن هذا الاختبار يفترض وجود

$$
\text { فرضيتين أساسيتين هما : }
$$
فرضية العدم : وتنص على انعدام الارتباط الذاتي

$\mathrm{HO}: \mathrm{P}=0$

H1: $\mathrm{P} \neq 0$

$$
\text { الفرضية البديلة : وتنص على وجود الارتباط الذاتي }
$$

حيث يتم المقارنة من خلال هذا الاختبار بين قيمة (DW) المحسوية والتي تساوي 1.991 وقيمة (DW) المستخرجة مع الأخذ بنظر الاعتبار عدد المشاهدات N = وعدد المتغيرات المستقلة

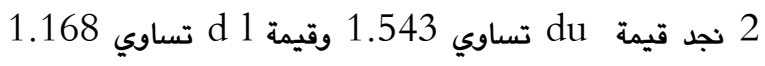

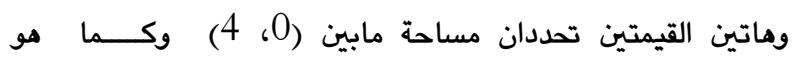
موضــــح فـــي الشكل (1) فــأن قيمـة (DW) المحسوية تقع ضمن منطقة عدم وجود ارتباط ذاتي

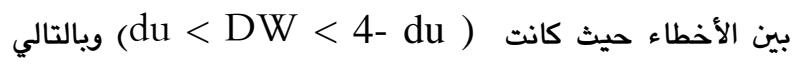
النموذج لا يحتوي على مشكلة الارتباط الذاتي للأخطاء .
4. اختبار النموذج من الناحية القياسية : بعد أن تأكدنا من قبول نموذج الجذر التربيعي، سنقوم باختباره من الناحية القياسية لمعرفة مدى انسجامه وتطابقه مع الفرضيات الخاصة به وكما يلي : بانيا أ. اختبار الازدواج الخطي : لغرض بناء نموذج ذو مصداقية عالية وخاصة عند اعتماده في التطبيق والتنبؤ، ينبغي عدم وجود ارتباط بين متغيرات الدراسة، وهناك عدة طرق يمكن من خلالها الكثف وتشخيص الارتباط الخطي المتعدد أو الازدواج الخطي بين متغيرات الدراسة، ونكتفي بالإثارة الم طريقة واحدة فقط وهي استخدام معامل ويرمز له اختصارا (VIF) (variance inflation factor ) حيث يتم في البداية حساب قيمة (Tolerance) لكل من المتغيرات المستقلة بالشكل الاتي:

Tolerance value $=1-\mathrm{R}^{2}$

VIF $=1 \div$ Tolerance $\square$

$$
\text { ثم يستخرج VIF وفق الصيغة الآتية : }
$$
ويعتبر هذا المعامل مقياساً لتأثي الارتباط بين المتغيرات المستقلة

$$
\text { على زيادة تباين معلمة المتغير المستقل . }
$$

ان الحصول على قيمة VIF لأحد المتغيرات المستقلة بمقدار تزيد عن تن خمسة تشير الى أن تقدير المعلمة المرافقة يتأثر بمشكلة الازدواج الخطي وأن قيمة VIF أقل من ذلك يشير إلى عدم تأثر أي منها بمشكلة الازدواج الخطي ل الخطي ولغرض التأكد من وجود مشكلة الازدواج الخطي من عدمه فقد تّ

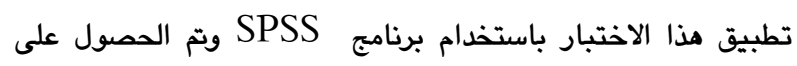
المعلومات الآتية الموضحة في الجدول (15) :

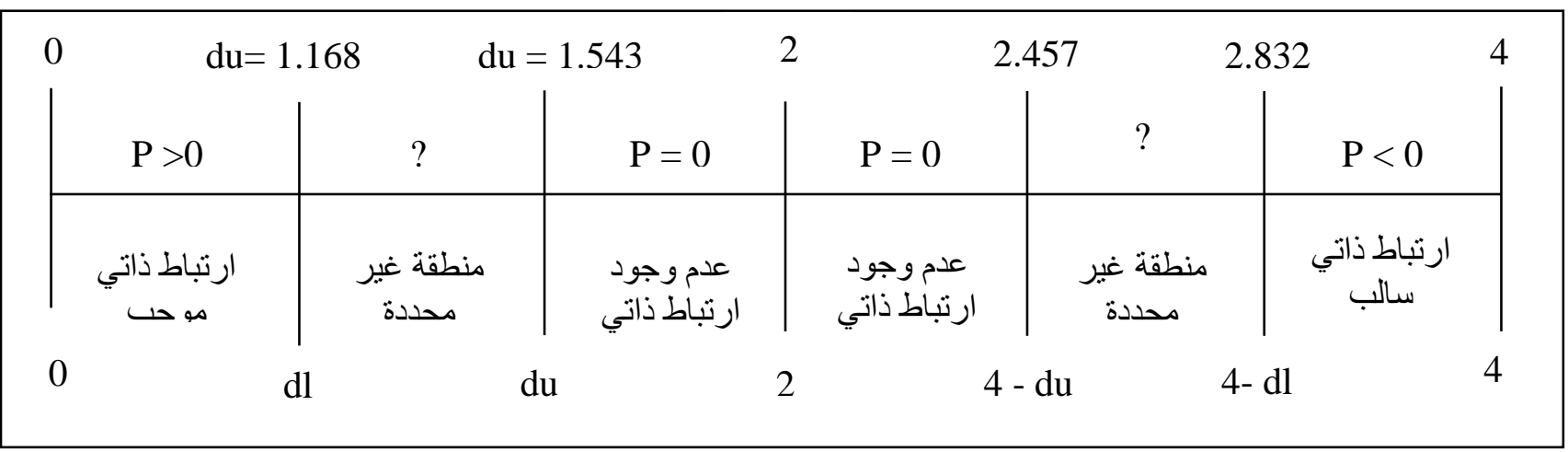

cm 2.7

شكل (1) مناطق القبول والرفض لاختبار ديربن واتسون

ج. اختبار عدم تجانس التباين : سيتم الاعتماد على الشكل الانتشاري بين قيم البواقي للنموذج والقيم المتنبئة لغرض اختيار مشكلة عدم تجانس التباين، ويعد القيام بهذه الخطوة من خلال برنامج SpsS حصلنا على الشكل الانتشاري (2) ويتبين لنا من 


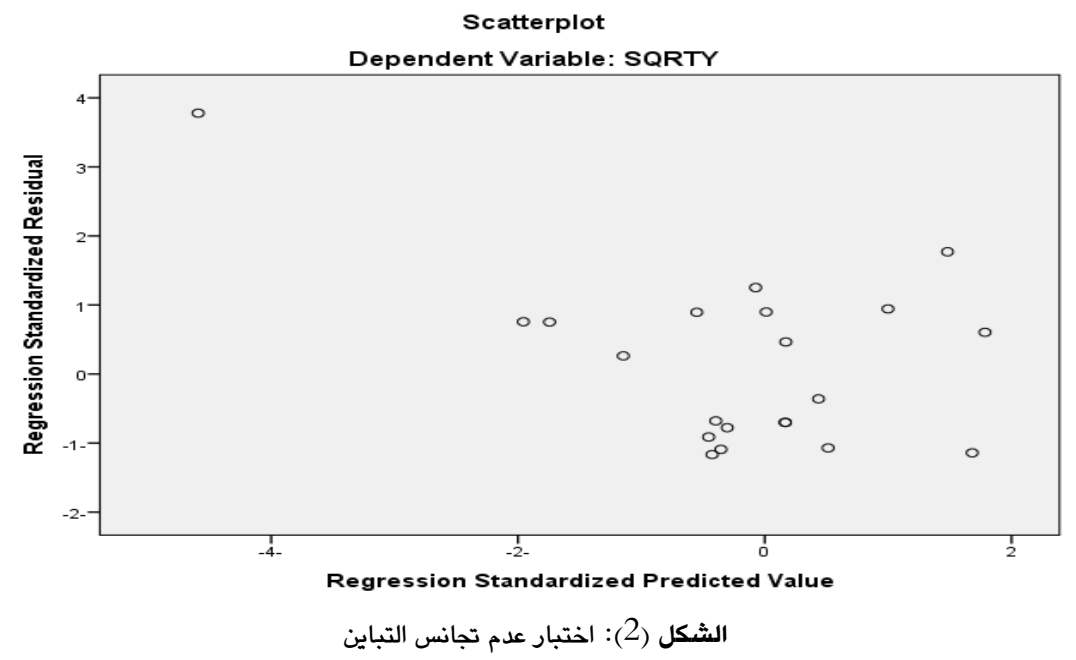

الشكل الانتشاري عدم وجود شكل ذات نمط خاص مما يشير إلى قناعة بعدم وجود مشكلة عدم تجانس التباين أي أن التباين ثابت 2.5

$$
\text { يقترح الباحث الاتي : }
$$

\section{5.الاستنتاجات والتوصيات}

1. من الضروري تغيير الصورة النمطية عن عمل المرأة وضرورة إفساح المجال للنساء في سوق العمل للاستفادة من تلك الطاقات

2. ضرورة السيطرة على العوامل والتحكم بالمتغيرات المذكورة في البحث والتي تؤثر بشكل مباشر أو غير مباشر على مستوى البطالة،

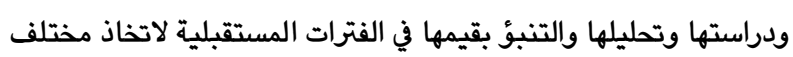
التدابير اللازمة التي من شأنها التخفيف من حدة البطالة.

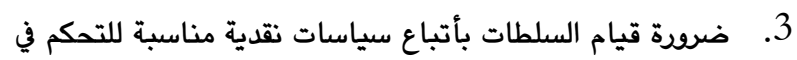
عرض النقد ومحاولة تخفيض سعر الفائدة قدر الإمكان من أجل تخفيض كلف الاستثمار وزيادة الإنتاج وتوفير فرص عمل جديدة . 4. زيادة مستوى الاستثمار في الاقتصاد الأردني وخاصة في القطاعات كثيفة الاستخدام للعمالة مثل القطاع الزراعي والصناعي وإدخال التحسينات والتقنيات الحديثة في تلك القطاعات ومنح التسهيلات من قبل الحكومة لتلك القطاعات لتشجيع نمو الإنتاج المحلي

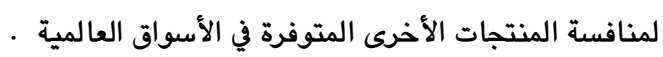
5. تنمية ودعم دور القطاع الخاص لخلق فرص العمل، وتشجيعه من خلال منح تسهيلات كتخفيض الضرائب وتبني سياسة الشراكة الحقيقية مع القطاع الخاص لأنه يعتبر المحرك الرئيسي للنمو · الاقتصادي 6. تشجيع المشاريع الصغيرة والمتوسطة والتي لا تحتاج إلى رؤوس أموال كبيرة بهدف امتصاص البطالة وخصوصا بين الشباب من خلال قيام الحكومة بإقراض الشباب العاطلين بالأموال الكافية ويفوائد منخفضة. 7. تقليص عدد سنوات الخدمة في الوظائف الحكومية، وتشجيع

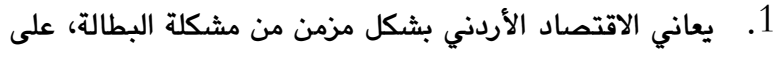
الرغم من اتجاه مذه المشكلة إلى التراجع خلال السنوات الأخير من الدراسة وخاصة سنة 2012 . 2. إن معدلات البطالة في الأردن كانت متفاوتة بين الذكور والإناث خلال المدة موضوع الدراسة، إذ كانت مرتفعة لدى الإناث مقارنة مع الذكور وكان متوسط معدلات البطالة تزيد بمقدار الضعف لدى الإناث مقارنة مع الذكور، وهذا يرجع أما إلى عدم رغبة الإناث بالانضمام إلى قوة العمل بسبب العادات والتقاليد، أو بسبب ظروف سوق العمل حيث تنخفض أجور الإناث، أو بسبب طول مدة ساعات الدوام الرسمية وعدم قدرة النساء التوفيق بين تلك الساعات والالتزامات المنزلية الملقاة على عاتقهن، أو بسبب عدم توفر فرص عمل مناسبة وملائمة. 3. تبين من خلال معاملات الارتباط بأن كل من (النفقات الاستثمارية

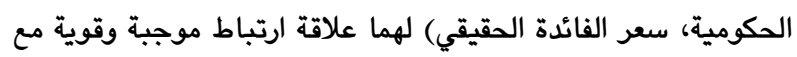
معدل البطالة في الأردن · معن 4. يميل المستثمرون إلى استثمار أموالهم حتى في ظل ارتفاع سعر الفائدة الحقيقي ومذا يؤدي إلى التخفيف من معدلات البطالة . 5. تبين من خلال معامل التحديد بأن كل من (النفقات الاستثمارية الحكومية، سعر الفائدة الحقيقي) لهما دور كبير بتفسير التغير في معدل

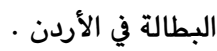
6. إن المتغيرات المستقلة الأكثر تأثيرا على معدل البطالة في الأردن هما (النفقات الاستثمارية الحكومية، سعر الفائدة الحقيقي) لذا تعتبر تلك المتغيرات محددات مهمة لمستوى البطالة . التقاعد المبكر لإفساح المجال أمام الخريجين الجدد ليستغلوا تلك 
7. درويش، سالم سليمان، (2013)، تطور نمو عرض النقود بالمملكة العربية

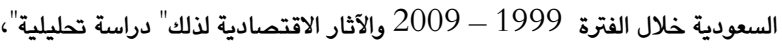
مجلة الجامعة الإسلامية للدراسات الاقتصادية والإدارية، المجلد (21)، العدد (1) .

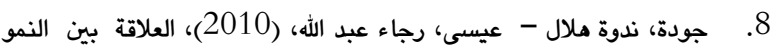

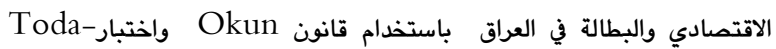
Yamamoto

9. حسين، رحيم - عبادي، محمد، (2013)، أثر المتغيرات الاقتصادية على

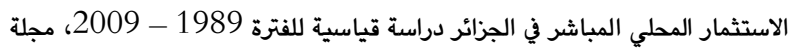

دراسات للعلوم الإدارية، المجلّد (40)، العدد (2). 10. عثامنة، عبد الباسط عبدالله - الزعبي، بشير خليفة، (2009)، العارية، العلاقة بين الاستثمار والتشغيل في الاردن : دراسة تحليلية قياسية للمدة 1973 - 2005،

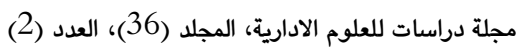

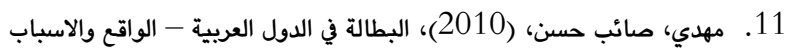

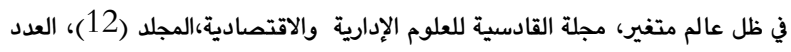

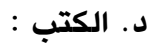
1. الوزني، خالد واصف - الرفاعي، احمد حسين، (2006)، مبادئ الاقتصاد الكلي، دار وائل للطباعة والنشر، عمان، الاردن .

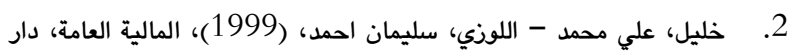
زهران للنشر والتوزيع، عمان، الاردن .

3. حسين، مجيد علي - سعيد، عفاف عبدالجبار، (2004)، مقدمة في التحليل

الاقتصادي الكلي، دار وائل للنشر و التوزيع، عمان، الأردن.

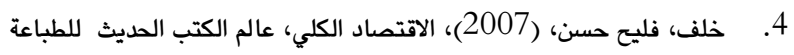

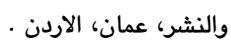
5. عبدالرحمن، اسماعيل - عريقات، حربي محمد، (2004)، مفاهيم ونظم اقتصادية، دار وائل للطباعة والنشر، عمان، الاردن .

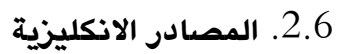

\section{A. Articles :}

1. Ayemere, Ibadin Lawrence - Moni Osedebamhen Matthew \& Eikhomun Daniel Ehi , 2014 , Real Sector, Gross Fixed Capital Formation and the Nigerian Stock Market, Vol.6, No.33.

2. Hosoya , Bykei, 2002, Tax Financed Government Health Expenditure and Growth with Capital Deepening Externality, Economics Bulletin, Vol.5, Iss. 14 .

3. Rauch, Jason N. \& Chi, Ying F. , 2010 , The Plight of Green GDP in China ,The Journal of Sustainable Development, Vol. 3 , Iss.1.

\section{B.Books :}

1. Delong, J.Bradford, 2002, Macroeconomics, Mc Graw-Hill Companies, Inc., New York, USA

2. Willsmore , A.W. , 1973 , Business Budgets in Practice, $5^{\text {th }}$ ed. , Pitman Publishing, Canada .
الوظائف التي تم استحداثها، مع الأخذ بنظر الاعتبار الحاجة لبعض الاختصاصات النادرة.

8. وضع ضوابط لمنع ازدواجية الوظائف، بحيث لايجمع الموظف الحكومي وظيفة اخرى بجانب وظيفته الحكومية الحالية . 9. الاهتمام بشكل اكبر بفئة الشباب وإعدادمم الإعداد المطلوب من وفئه جميع النواحي وخاصة العلمية لتمكينهم من الحصول على فرص العمل المتناسبة مع قدراتهم وقابلياتهم المختلفة. 10. إعادة تقييم سياسات وجودة وكفاءة نظام التعليم وتطوير المناهج من خلال خلق استراتيجيات يربط مخرجات التعليم مع وجيات وهاءهات سياسات التشغيل ويما يتوافق مع متطلبات سوق العمل المحلي .

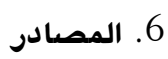

1.6 - المصادر العربية أ. النشرات الرسمية : الن العرية

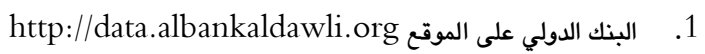

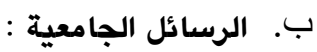
1. الأسطل، محمد مازن محمد، (2014)، العوامل المؤثرة على معدل البطالة

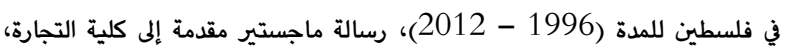
الجامعة الإسلامية بغزة . 2. عبدالرحمن، إسماعيل مصطفى، (2002)، بطالة القوى العاملة في أقليم

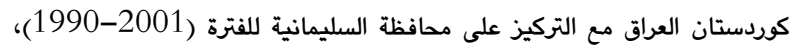
رسالة ماجستير مقدمة إلى كلية الإدارة والاقتصاد، جامعة السليمانية.

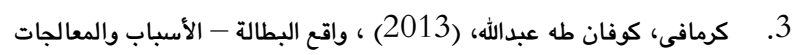

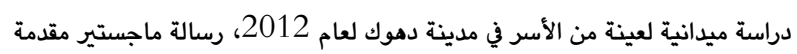
إلى فاكلتي القانون والإدارة، جامعة دهوك.

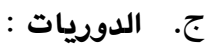

1. البريفكاني، احمد محمد اسماعيل - رشيد، خمى ناصر - الاتروشي، جاسم

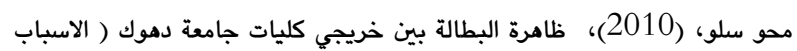
والمعالجات)، مجلة تنمية الرافدين، المجلد (23)، العدد (100)، (10) .

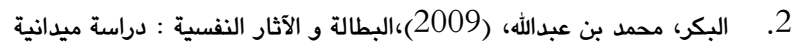
تحليلية، المجلة العربية للدراسات الامنية والتدريب، المجلد (26)، العدد (51).

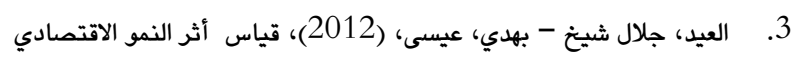

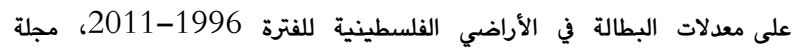

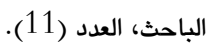
4. الكرخي، مجيد عبد جعفر، (2001)، الإنفاق الحكومي والتحديات الاجتماعية

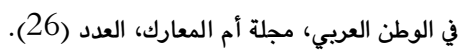

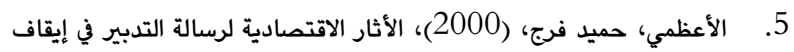

التضخم الجامع في الاقتصاد العراقي، مجلة دراسات اقتصادية، العدد (2) .

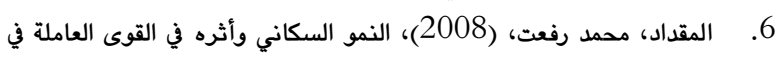

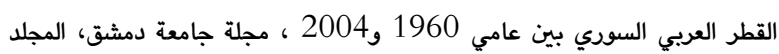

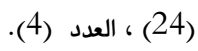




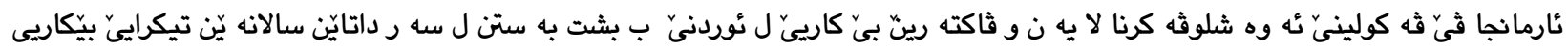

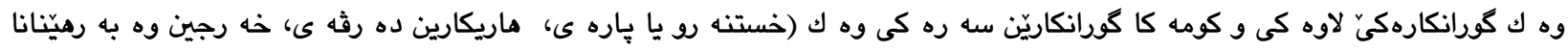

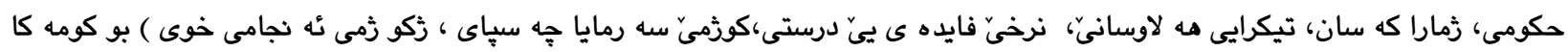

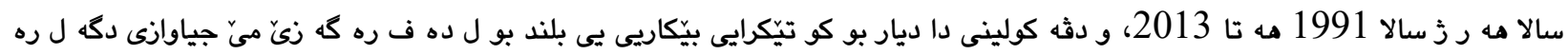

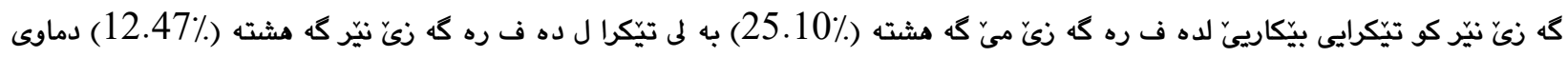

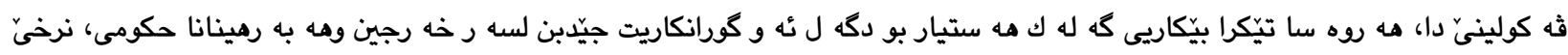

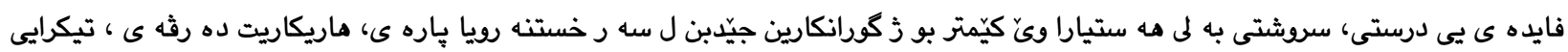

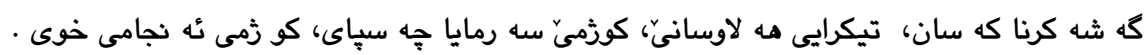

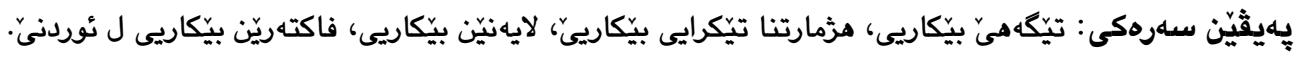

\title{
Unemployment in the Hashemite Kingdom of Jordan from 1991 Until 2013
}

\begin{abstract}
:
This study aims to analyze the trends and determinants of unemployment in the Hashemite Kingdom of Jordan, based on annual data for the unemployment rate as a depended variable and a number of independent variables as (money supply, foreign aid, government investment expenditure, the number of the population, inflation rate, the real interest rate, gross fixed capital formation, gross domestic product ) for a series of time stretching from 1991 until 2013, and was found by the study that unemployment rates were higher in females compared with males reaching the arithmetic average of the rate of unemployment among females $(25.10 \%)$, while the average for males (12.47\%) During the period of study; In addition, the rate Unemployment was highly sensitive to changes in government investment expenditure, real interest rate while he was less sensitive to changes in the money supply, foreign aid, the population growth rate, inflation rate, gross fixed capital formation, gross domestic product.
\end{abstract}

Keywords: the concept of unemployment, the unemployment rate measure, unemployment paths, the determinants of unemployment in Jordan. 